\title{
Mesenchymal Stem Cell Transplantation in Newly Diagnosed Type-1 Diabetes Patients: A Phase I/II Randomized Placebo Controlled Clinical Trial
}

Mahmoud Izadi

Royan Institute for Stem Cell Biology and Technology https://orcid.org/0000-0002-7203-0220

Anavasadat Sadr Hashemi Nejad

Royan Institute for Stem Cell Biology and Technology

Maedeh Moazenchi

Royan Institute for Stem Cell Biology and Technology

Safdar Masoumi

Royan Institute for Stem Cell Biology and Technology

Ali Rabbani

Tehran University of Medical Sciences

\section{Farzad Kompani}

Tehran University of Medical Sciences

Amir Abbas Hedayati AsI

Royan Institute for Stem Cell Biology and Technology

\section{Fatemeh Abbasi}

Royan Institute for Stem Cell Biology and Technology

Neda Jarooghi

Royan Institute for Stem Cell Biology and Technology

Mohamad Ali Mohseni Meybodi

Royan Institute for Stem Cell Biology and Technology

Aria Setoodeh

Tehran University of Medical Sciences

Farzaneh Abbasi

Tehran University of Medical Sciences

\section{Seyedeh Esmat Hosseini}

Royan Institute for Stem Cell Biology and Technology

Fatemeh Moeini Nia

Royan Institute for Stem Cell Biology and Technology

Reza Salman Yazdi

Royan Institute for Reproductive Biomedicine

Roghayeh Navabi 
Royan Institute for Stem Cell Biology and Technology

\section{Ensiyeh Hajizadeh-Saffar}

Royan Institute for Stem Cell Biology and Technology

Hossein Baharvand ( $\sim$ h.baharvand@royan-rc.ac.ir)

University of Science and Culture https://orcid.org/0000-0001-6528-3687

\section{Research}

Keywords: Type 1 Diabetes, Mesenchymal Stem Cells, Cell Therapy, Immunomodulation, Randomized Controlled Trial, Regulatory T Cells

Posted Date: September 27th, 2021

DOl: https://doi.org/10.21203/rs.3.rs-921850/v1

License: (c) (1) This work is licensed under a Creative Commons Attribution 4.0 International License. Read Full License 
1 Mesenchymal Stem Cell Transplantation in Newly Diagnosed Type-1 Diabetes Patients:

2 A Phase I/II Randomized Placebo Controlled Clinical Trial

3

4 5

a. Department of Stem Cells and Developmental Biology, Cell Science Research Center, Royan Institute for Stem Cell Biology and Technology, ACECR, Tehran, Iran.

b. Advanced Therapy Medicinal Product Technology Development Center (ATMP-TDC), Cell Science Research Center, Royan Institute for Stem Cell Biology and Technology, ACECR, Tehran, Iran.

c. Department of Epidemiology and Biostatistics, Tehran University of Medical Sciences, Tehran, Iran.

d. Growth and Development Research Center, Children's Medical Center of Excellence, Tehran University of Medical Sciences, Tehran, Iran.

e. Division of Hematology and Oncology, Children's Medical Center, Pediatrics Center of Excellence, Tehran University of Medical Sciences, Tehran, Iran.

f. Hematology-Oncology and Stem Cell Research Center, Tehran University of Medical Sciences, Shariati Hospital, Tehran, Iran.

g. Department of Regenerative Medicine, Cell Science Research Center, Royan Institute for Stem Cell Biology and Technology, ACECR, Tehran, Iran. 
h. Division of Pediatrics Endocrinology, Children's Medical Center, Pediatrics Center of Excellence, Tehran University of Medical Sciences, Tehran, Iran.

i. Student Research Committee, School of Nursing and Midwifery, Shahid Beheshti University of Medical Sciences, Tehran, Iran.

j. Department of Andrology, Reproductive Biomedicine Research Center, Royan Institute for Reproductive Biomedicine, ACECR, Tehran, Iran.

k. Department of Medical Biotechnology, School of Advanced Technologies in Medicine, Tehran University of Medical Sciences, Tehran, Iran.

1. Department of Diabetes, Obesity, and Metabolism, Cell Science Research Center, Royan Institute for Stem Cell Biology and Technology, ACECR, Tehran, Iran.

m. Department of Developmental Biology, University of Science and Culture, Tehran, Iran.

$\dagger$ These authors contributed equally to this work as co-first authors.

* Corresponding authors:

Ensiyeh Hajizadeh-Saffar, Email: en.hajizadeh@ royan-rc.ac.ir

and

Hossein Baharvand, Email: h.baharvand@ royan-rc.ac.ir

\section{Abstract}

\section{Background:}

5 Type-1 diabetes (T1D) occurs following autoimmune-induced pancreatic beta cells death. 6 Among several treatment modalities, Mesenchymal Stem Cells (MSCs) transplantation is promising for autoimmune disorders due to immunomodulation, regeneration, and migration to damaged tissue upon systemic injection. This study assessed the safety and efficacy of 
intravenous injection of autologous bone marrow-derived MSCs in newly diagnosed T1D

50 patients.

51 Methods:

52 After receiving informed consent, 21 patients who met the study criteria were enrolled and randomly assigned to receive either MSCs or placebo. Each patient in the experimental group received two doses of MSCs and followed for at least one year post-transplantation.

\section{Results:}

The results have shown that this transplantation is safe and significantly reduces the number of hypoglycemic episodes. MSCs transplantation improved glycated hemoglobin (HbA1c), shifted serum cytokine patterns from pro-inflammatory to anti-inflammatory, increased the number of regulatory T-cells in the peripheral blood, and improved quality of life. Early transplantation of MSCs significantly improved HbA1c and C-peptide levels and shifted proinflammatory cytokines to anti-inflammatory cytokines. Also, exercise combined with MSCs transplantation improved glycemic and immunologic indices.

\section{Conclusions:}

In conclusion, autologous MSC transplantation is safe and effective, and its early transplantation is a promising treatment in newly-diagnosed T1D children suffering from hypoglycemic episodes.

\section{Trial registration:}

This clinical trial was registered at the Iranian Registry of Clinical Trials (IRCT) with the identifier IRCT ID: IRCT2016070428786N1 registered on August 20, 2016 (Retrospectively registered) (https://en.irct.ir/trial/23256) and at the U.S. National Institutes of Health (ClinicalTrials.gov) with the related identifier NCT04078308 registered on September 6, 2019 (Retrospectively registered). (https://clinicaltrials.gov/ct2/show/NCT04078308) 
74 Keywords: Type 1 Diabetes, Mesenchymal Stem Cells, Cell Therapy, Immunomodulation, 75 Randomized Controlled Trial, Regulatory T Cells

76

77

\section{Introduction}

Type-1 diabetes (T1D) is a metabolic disease characterized by the autoimmune destruction of insulin-secreting pancreatic beta $(\beta)$ cells. Hyperglycemia is a common problem of diabetics due to a lack of or low insulin secretion (1-7).

The International Diabetes Federation (IDF) introduces diabetes as one of the fastest-growing global health emergencies of this century and estimates that in 2019, 463 million people worldwide had diabetes. This number is expected to increase to 578 million by 2030 and 700 million by 2045 (8). Among adults diagnosed with diabetes, about 5.2\%-5.6\% have T1D (9, 10). The American Diabetes Association (ADA) reported an increased number of affected children with T1D and an increase in prevalence in most sex, age, and ethnic subgroups, in addition to an increased incidence in almost all age groups (5).

In 2019, the IDF reported that 7808 children and adolescents between zero and 19 years old had T1D in Iran (8). The innate and adaptive immune systems are deregulated in T1D, resulting in pancreatic islet $\beta$-cell destruction through CD4 and CD8 T-lymphocytes, natural killer (NK) cells, and B-lymphocyte infiltration following the invasion of dendritic cells and macrophages (11-13). Immune cells and their secretory factors, such as pro-inflammatory cytokines, make an inflammatory environment that gradually mediates $\beta$-cell death. As a result, patients' physiological blood glucose regulation fails, and diabetes complications endanger their life expectancy and quality of life (QOL) $(11,13,14)$.

Diabetes causes severe chronic complications with irreversible multi-organ damage in patients. These complications include diabetic nephropathy, neuropathy, retinopathy, and cardiovascular diseases $(1,15-17)$. 
T1D Patients' survival depends on daily doses of exogenous insulin (EI) to balance their blood glucose levels. Although this is the standard treatment, it does not provide an adequate physiological response and cannot prevent the progressive degeneration of islet $\beta$-cells; consequently, these patients might experience hypoglycemic episodes (1, 2, 18-20).

Current therapies for T1D have significant limitations. Insulin injections are the first-line treatment with different challenges: long-term dependency, difficulty with EI level management, and potential insulin resistance with long-term usage. Second-line treatment, pancreas transplantation has faced multiple obstacles such as donor shortages, the possibility of transplant rejection, usage of immunosuppressive drugs, and high risks with an organ transplantation surgery $(4,21)$. Thus, improved diabetes treatment methods that can address these limitations will be applicable in diabetes research and future management (21).

Cell-based therapy could ameliorate diabetes complications by providing better glycemic control (22). Different cell therapy strategies for T1D include cell replacement, cell regeneration, and cell reprogramming. Various stem cells that have been tested for cellular therapy include hematopoietic stem cells (HSCs), induced pluripotent stem cells (iPSCs), and mesenchymal stem cells (MSCs) $(2,23,24)$. Other potential cell-based treatments for T1D include islet transplantation, transplantation of encapsulation devices, polyclonal regulatory $\mathrm{T}$ ( $\mathrm{T}$ reg) cell transplantation, and alterations to the immune system response (19, 25-29). To date, MSCs are the most studied cell population in clinical trials. The therapeutic capacity of MSCs is based on their ease of isolation, ability to differentiate into multiple cell types, low immunogenicity, abundant source, minimal ethical concerns, and, most notably, their release of biological factors that can alleviate impaired tissues (30). The findings of a preclinical study showed that MSCs could be effective as a distant immunomodulator in addition to their homing to injured sites (31). 
122 MSCs have a mesodermal origin and are defined as multipotent cells that can adhere to plastic;

123 self-renew; express specific surface antigen markers (CD73, CD90, CD105); lack

124 hematopoietic antigen expressions (CD45, CD34, CD14 or CD11b, CD79 $\alpha$ or CD19, HLA-

125 DR); and can differentiate into osteocytes, adipocytes, or chondrocytes (30, 32). MSCs are

126 derived from many sources such as the bone marrow, umbilical cord, umbilical cord blood,

127 adipose tissue, and dental pulp (33-35).

128 Immunomodulatory therapeutic approaches can be used to preserve residual $\beta$-cells in recent-

129 onset T1D patients with a greater amount of functional $\beta$-cell mass $(11,36)$.

130 MSCs have a superior biosafety profile and negligible risk of tumorigenicity compared with

131 induced pluripotent or embryonic stem cells (37). Researchers have proposed using MSCs as

132 an attractive therapy to ameliorate or reverse diabetes because of their systemic

133 immunomodulatory and regenerative properties, no immunogenicity due to a lack of major

134 histocompatibility complex (MHC) class II, and ability to home to damaged pancreatic islets

135 and local lymph nodes $(11,13,38-45)$.

136 We took into consideration the promising features of MSCs and designed a randomized

137 placebo-controlled phase I/II clinical trial. In this trial, we sought to examine the safety and

138 efficacy of autologous bone marrow-derived MSCs as a treatment for newly diagnosed patients 139 with T1D.

140

141 Materials and Methods

\section{Study design}

143 A triple-blinded parallel randomized placebo-controlled trial was conducted between July 2015

144 and January 2020 at Royan Institute, Tehran, Iran, in collaboration with the Growth and

145 Development Research Center of Tehran University of Medical Sciences, Tehran, Iran. The 
146 Research Ethics Committee at Royan Institute approved this study (approval code: 147 IR.ACECR.ROYAN.REC.1394.50), and the study was conducted under the Declaration of

148 Helsinki. The trial was registered at the Iranian Registry of Clinical Trials (IRCT) with the

149 identifier IRCT ID: IRCT2016070428786N1 and at the U.S. National Institutes of Health

150 (ClinicalTrials.gov) with the related identifier NCT04078308. Of note, we originally designed

151 this study as a crossover study; however, our data analysis showed that the residual effects of

152 the MSC transplantation were present after the 12-month follow-up. Therefore, the MSC versus

153 placebo comparison was compared during the initial 12-month follow-up, and early versus late

154 transplantation was compared in the second-year follow-up. Figure $1 \mathrm{~b}$ provides a brief 155 description of the trial steps and timeline.

\section{Study population}

158 A total of 21 patients (age: 8 to 40 years) enrolled in this study. The patients were diagnosed 159 with T1D according to diagnostic criteria and the ADA guidelines (5) within six weeks before 160 enrollment and were already under classic insulin therapy. Patients were enrolled between July 1612015 and January 2018 if they met the following inclusion criteria: evaluated fasting C-peptide

162 level $\geq 0.3 \mathrm{nmol} / \mathrm{L}$ and presence of at least one of three autoantibodies against pancreatic $\beta$ cells 163 (islet cell antibody [ICA], glutamic acid decarboxylase antibody [GADA], or insulinoma associated-2 antibody [IA-2A]). The exclusion criteria consisted of pregnancy or breastfeeding; cancer; any acute or severe diseases (cardiac, pulmonary, hepatic, kidney, mental, or other

166 diseases); positive test results for human immunodeficiency virus (HIV), human T-

167 lymphotropic virus (HTLV), hepatitis B virus (HBV), hepatitis C virus (HCV), or 168 cytomegalovirus (CMV); other immune-deficiencies; hyperesthesia; or history of severe 169 ketoacidosis. Figure 1a presents the CONSORT flow diagram of the study population and their 170 respective group assignment. All participants or their parents or legal guardians (when required 
171 for pediatric participants) received comprehensive oral and written information about the nature

172 and possible consequences of the study. They signed a written informed consent form before 173 participating in this clinical trial.

\section{Randomization and masking}

175 Patients were randomly assigned to either the MSC or the placebo group by block

176 randomization. A block size of four was used for randomization, and the sequences were

177 calculated by Random allocation software v. 2.0. The research coordinator had exclusive access

178 to the numbered, sealed, opaque envelopes that indicated each patient's randomized treatment 179 assignment.

\section{Blinding}

181 In this triple-blinded study, the participants, care providers, and outcomes assessors were

182 blinded to the treatment assignments. To protect the blinding, two different physicians

183 conducted the intervention, patient assessments, and follow-ups. The vials that contained either 184 the MSCs or the placebo were similar. Only the specific randomization code assigned to an 185 individual patient was visible on the vial. The person who prepared the cells and the research 186 coordinator were aware of the vials' exact contents.

\section{Study interventions}

188 Participants were randomly assigned to receive either two doses of $1 \times 10^{6}$ autologous MSCs or

189 a placebo per kilogram of the patient's body weight at weeks 0 and 3. Besides, we compared 190 the effects of early versus late transplantation of MSCs. Newly diagnosed T1D patients who 191 received the MSCs transplantation during the first year were considered the early 192 transplantation group (Early Tx). The late transplantation group (Late Tx) were patients who

193 received the placebo during the first year of the study and were then assigned to receive the

194 MSCs transplantation at least one year after their diabetes diagnosis. According to the eligibility 
195 criteria, all patients underwent baseline laboratory blood tests (Table S8), EKG, and chest X-

196 ray assessments to confirm their general health. After randomization, bone marrow was

197 aspirated from all the participants' iliac crests while under general anesthesia.

\section{Mesenchymal stem cell (MSC) preparation and transplantation}

199 Clinical-grade MSCs were isolated from bone marrow, expanded in passages 2-3, and

200 cryopreserved under good manufacturing practice (GMP) conditions at Royan Institute, as 201 previously described (46). The release criteria for the therapeutic use of isolated MSCs included 202 the absence of viral, microbial, fungal, and mycoplasma contamination; a less than acceptable 203 level of endotoxin; normal karyotype; and cell viability of more than 95\%. The MSCs were 204 assessed by flow cytometry for their ability to express CD105, CD90, CD44, CD73, and lack 205 of CD34 and CD45 expression.

206 Three to four weeks after bone marrow aspiration, $1 \times 10^{6}$ autologous MSCs in normal saline 207 per kilogram of the patient's body weight were administered for each dose of two intravenous 208 infusions at weeks 0 and 3. The placebo group received a similar amount of normal saline. The 209 first transplantation was regarded as day zero in this study.

\section{Patient follow-up}

211 The patients were followed for one year after the first infusion to assess safety and efficacy

212 parameters. During this time, the patients were seen at weeks 1, 2, and 4, and months 2, 3, 6, 9, 213 and 12 for physician visits and laboratory blood analyses. Furthermore, the patients recorded 214 blood glucose self-monitoring (at least two or three times per day) during this period to evaluate 215 treatment safety and efficacy.

$217 \quad$ Study outcomes 
The patients provided medical histories and underwent physical examinations at each outpatient

220 visit to monitor for treatment-related adverse events and hypoglycemic episodes. Safety was assessed based on the Common Terminology Criteria for Adverse Events version 5 (CTCAE v.5). The number of hypoglycemic episodes was assessed by evaluating patients' blood glucose monitoring sheets. Hypoglycemia was defined as each blood glucose recording below $70 \mathrm{mg} / \mathrm{dl}$ according to CTCAE v.5.

\section{Secondary outcome: Efficacy}

226 Efficacy was defined as changes from baseline in fasting blood sugar (FBS), two-hour postprandial glucose test (2hpp), C-peptide, and serum levels of Glycated hemoglobin (HbA1c), daily dose of injected EI, and lability index (LI).

FBS and 2hpp were evaluated using GLUC3 kit (04404483190, Roche Diagnostics GmbH), C230 peptide using Elecsys C-peptide kit (03184897, Roche Diagnostics GmbH), HbA1c using Tinaquant ${ }^{\circledR}$ HbA1c Gen. 3 (05336163190, Roche Diagnostics GmbH). These parameters were measured by COBAS® 6000 analyzer and COBAS INTEGRA® 400 plus analyzer Roche

\section{Diagnostics.}

234 Serum levels of interleukin 6 (IL-6), tumor necrosis factor-alpha (TNF- $\alpha$ ), interleukin 4 (IL-4), 235 interleukin 10 (IL-10), and transforming growth factor-beta 1 (TGF- $\beta 1$ ) were evaluated using 236 Enzyme-linked immunosorbent assay (ELISA) utilizing the following kits: Human IL-6 ELISA 237 Kit(E0090Hu, Bioassay Technology Laboratory); Human TNF- $\alpha$ ELISA Kit (E0082Hu, 238 Bioassay Technology Laboratory), Human IL-4 Quantikine ELISA Kit (D4050, R\&D 239 Systems), Human IL-10 Quantikine ELISA Kit (D100B, R\&D Systems), and Human TGF- $\beta 1$ 240 Quantikine ELISA Kit (DB100B, R\&D Systems).

241 Patients' QOL was assessed by the 36-item Short Form Survey (SF-36) and Diabetes QOL 242 (DQOL) questionnaires. The effects of physical exercise on metabolic and immunologic indices 243 between the MSC transplantation and placebo groups were compared in some patients. 
244 The percentages of CD4+ CD25+ Foxp3+ T reg cells were also assessed in patients' peripheral 245 blood before the MSCs transplantation and 48 hours after transplantation, as described before 246 (47). Briefly, Ficoll density gradient (Cat\#: P04-60100, PAN biotech) was used to separate 247 peripheral blood mononuclear cells (PBMCs) from collected blood in EDTA-containing tubes. 248 The PBMCs were incubated with FITC conjugated anti-CD4 (Cat\#: 550628, BD Biosciences) 249 and PE-conjugated anti-CD25 (Cat\#: 557138, BD Biosciences) antibodies to stain the surface 250 markers. Then, the PBMCs were incubated with fixation and permeabilization buffer BD 251 Cytofix/Cytoperm ${ }^{\mathrm{TM}}$ (Cat\#: 554722, BD Biosciences), washed with BD Perm/Wash buffer 252 (Cat\#: 554723, BD Biosciences), and stained with PerCP anti-Foxp3 antibody (Cat\#: NBP2253 34432PCP, Novus Biologicals). The stained PBMCs were characterized by a flow cytometer 254 (BD FACSCalibur ${ }^{\mathrm{TM}}$, BD Biosciences, San Jose, CA, USA) equipped with BD CellQuest Pro 255 software. The acquired data were analyzed by FlowJo software (Version: 7.6.1, 256 BD Biosciences). Isotype controls were utilized to assist precise compensation and evaluate 257 antibody specificity.

\section{Sample size}

259 The calculated sample size was based on HbA1c improvement over 12 months in the MSC 260 group versus the placebo group. We assumed the anticipated effect size of $\mathrm{f}=0.52$, type I error 261 of 0.05 , test power of $80 \%$, and correlation coefficient of 0.5 for repeated measurements based 262 on $\mathrm{Hu}$ et al.'s study (11). A total sample size of $\mathrm{n}=20$ was calculated with $\mathrm{G}^{*}$ Power 3.1 263 (University of Kiel, Germany) using repeated measures analysis of variances (ANOVA). 
267 All data were collected and stored at Royan Institute. Primary and secondary outcome analyses 268 were performed on all randomized, eligible patients. All analyses were based on a statistical 269 analysis plan prepared by a statistician blinded to the study assignments, and all analytic 270 conclusions were based on masked data reviews.

271 We used the modified intention to treatment (MITT) method for the standard primary analysis. 272 Patients were analyzed according to their randomized arm. Missing data were excluded at each 273 time point, and the analysis was based on the available cases at each time point.

274 Analyses were performed using Stata software (StataCorp. 2015. Stata Statistical Software: 275 Release 14. College Station, TX: StataCorp LP.), and the graphs were generated with GraphPad 276 Prism version 9.1.1 for Windows, GraphPad Software, San Diego, California, USA, 277 www.graphpad.com. The significance level for all analyses was set at $\alpha=0.05$. Baseline 278 continuous characteristics are reported as mean \pm standard deviation, and categorical variables 279 are reported as $\mathrm{N}$.

280 Interventional effects on primary and secondary outcomes were evaluated using a generalized 281 estimating equation (GEE) for longitudinal data with an identity link and an exchangeable 282 correlation matrix to give population-averaged estimates. The placebo group was considered 283 the reference group to evaluate the effects of the intervention. The Early Tx group was used as 284 the reference group to evaluate the effects of new-onset on intervention. Also, we assessed the 285 residual data from the GEE model. GEE models were used to evaluate changes from baseline 286 to 3, 6, 9, and 12 months for primary and secondary continuous outcomes measured 287 longitudinally. Groups were included in the models as the covariate, and visit time was the 288 categorical measure. The interaction between groups and time was considered in the model, 289 and confidence intervals (CI) and P-values were adjusted by the confounders of body mass 290 index (BMI), age, and sex. 


\section{Study population}

294 A total of 212 patients were screened for eligibility from July 2015 to January 2018, in which

29521 met the eligibility criteria and were randomly assigned to either the MSC transplantation or 296 the placebo group (Figure 1a). The patients were followed up for a year after they received their 297 first injection. Figure $1 \mathrm{~b}$ provides a brief description of the trial steps and timeline.

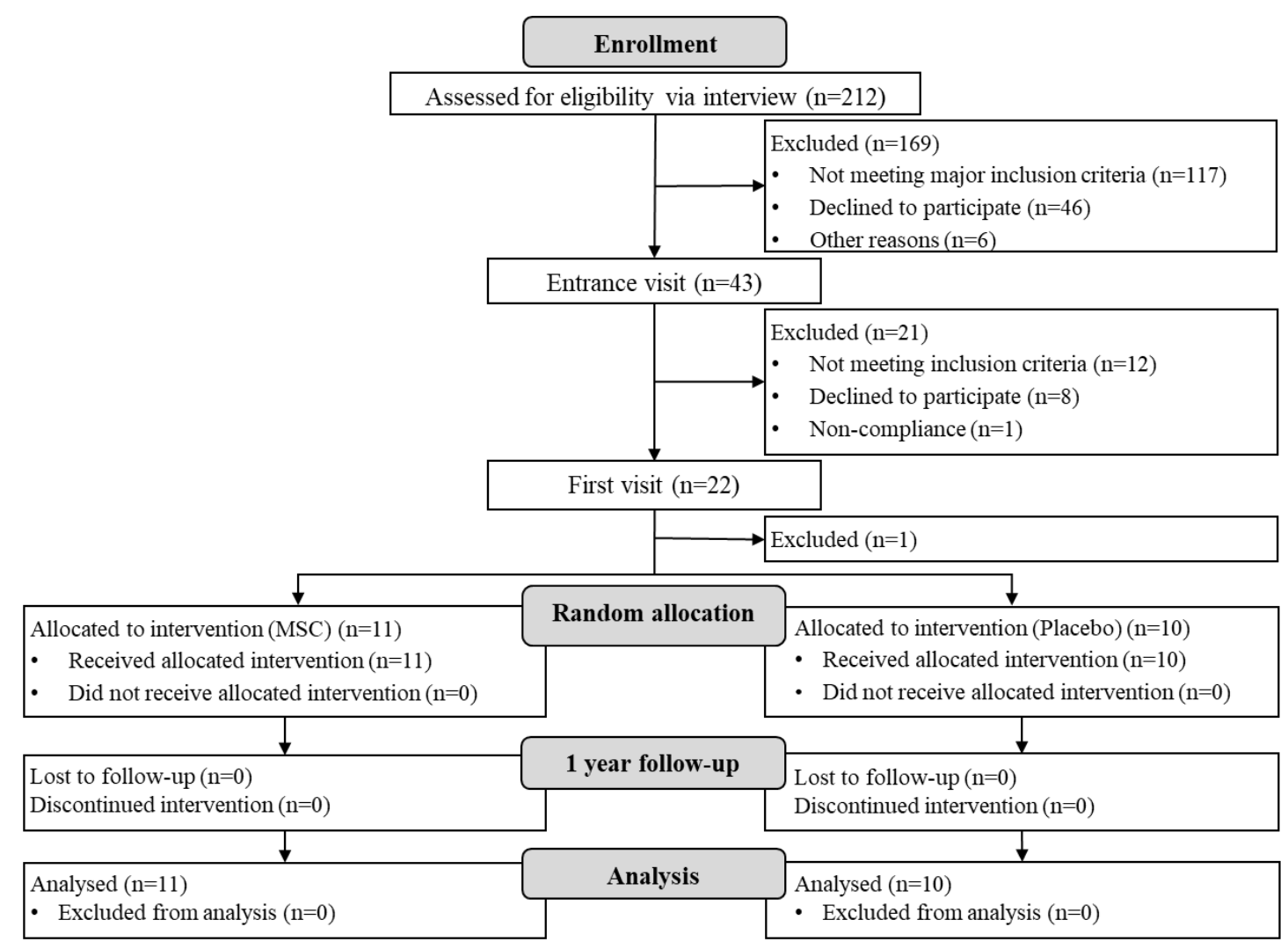

b 


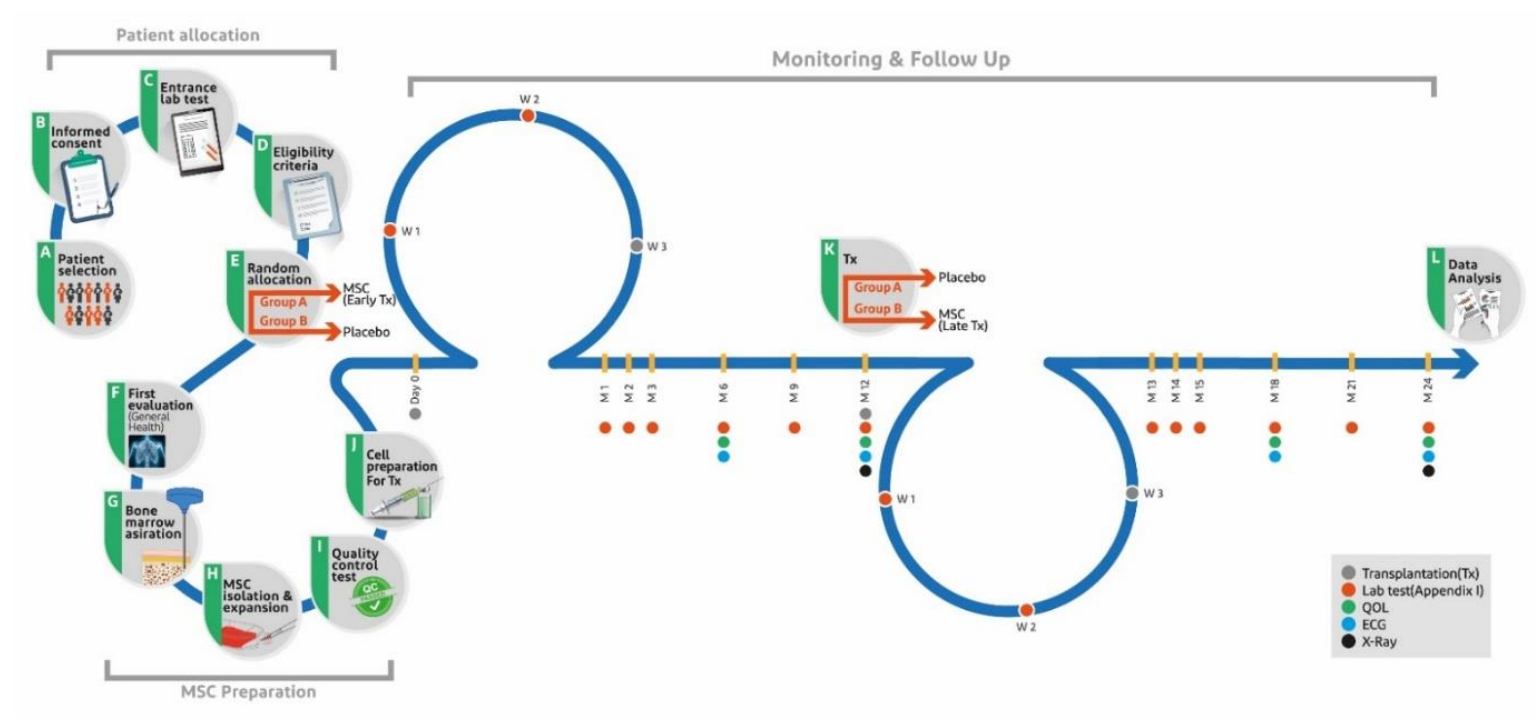

Figure 1. a. CONSORT flow diagram. A total of 212 patients were assessed for eligibility, of which 43 were selected for further verification of the eligibility criteria. Finally, 21 participants were selected and randomly assigned to either the mesenchymal stem cell (MSC) or placebo group. The participants were followed for one year and then analyzed for study outcomes. b. Schematic description of the study. The process of this clinical trial is generally divided into three main steps, including Patient allocation, MSC preparation, and Monitoring and Follow up. Briefly, selected patients gave informed consent, and after checking full eligibility criteria, they were randomly allocated to either receive MSC or Placebo. Then patients who underwent the first evaluation were subjected to bone marrow aspiration. MSCs were isolated from harvested bone marrow and expanded via culturing in a cleanroom facility. The cells that passed quality-control tests were intravenously injected into group A (early transplantation), while patients in group B received normal saline as a placebo. All patients were followed up for one year, and then the patients in group A received a placebo, whereas patients in group B received MSC (late transplantation). Data were analyzed after 12 and 24 months of follow-up.

301 Baseline demographic and clinical characteristics were similar in both groups (Table 1).

Table 1. Baseline demographic characteristics of the study participants $(n=21)$

\begin{tabular}{lcc}
\hline & Placebo $^{\mathbf{a}}$ & MSC $^{\mathbf{a}}$ \\
& $(\mathbf{n = 1 1})$ & \\
\hline Demeral characteristics & $(\mathbf{n = 1 0})$ & \\
Age (years) & $11.50 \pm 2.63$ & $10.27 \pm 1.67$
\end{tabular}


BMI $\left(\mathrm{kg} / \mathrm{m}^{2}\right)$

Male / Female
$18.91 \pm 3.41$

$5 / 5$
$16.75 \pm 2.57$

$6 / 5$

\section{Residence}

Local (Tehran Province)/other

$3 / 7$

$6 / 5$

Auto-antibodies (AA) (negative/positive)

ICA

GADA

IA-2A*
$6 / 4$

$0 / 10$

$5 / 3$
$6 / 5$

$3 / 8$

$3 / 7$

$\begin{array}{lcc}\text { Metabolic indices } & \\ \text { FBS }(\mathrm{mg} / \mathrm{dl}) & 149.4 \pm 51.97 & 165.27 \pm 97.49 \\ \text { 2hpp (mg/dl) } & 234.7 \pm 80.39 & 269.00 \pm 173.29 \\ \text { HbA1c (\%) } & 7.85 \pm 1.45 & 8.63 \pm 2.19 \\ \text { C-peptide (ng/ml) } & 0.92 \pm 0.57 & 0.72 \pm 0.38 \\ \text { EI (IU/kg/day) } & 0.71 \pm 0.30 & 0.78 \pm 0.44 \\ \text { LI (mmol/l2/h.week-1) } & 42.09 \pm 44.31 & 29.44 \pm 35.50\end{array}$

\section{Cytokines}

Pro-inflammatory

IL-6 (ng/l)

$86.66 \pm 30.11$

$106.96 \pm 57.67$

TNF- $\alpha(\mathrm{pg} / \mathrm{ml})$

$68.29 \pm 34.49$

$94.30 \pm 55.55$

Anti-inflammatory

IL-4 (pg/ml)

$325.02 \pm 179.45$

$249.84 \pm 208.04$

IL-10 (pg/ml)

$412.38 \pm 336.84$

$236.22 \pm 221.86$

TGF- $\beta 1(\mathrm{pg} / \mathrm{ml})$

$802.58 \pm 386.44$

$539.96 \pm 529.99$

Quality of life questionnaires

DQOL

SF-36
$75.97 \pm 11.16$

$77.09 \pm 13.46$
$75.91 \pm 9.69$

$74.43 \pm 17.98$
${ }^{\mathrm{a}}$ Variables are expressed as mean \pm standard deviation and
EI: Exogenous insulin
count
LI: Lability index
BMI: Body mass index
IL-6: Interleukin 6
ICA: Islet cell antibody
TNF- $\alpha$ : Tumor necrosis factor-alpha 


\begin{tabular}{ll}
\hline GADA: Glutamic acid decarboxylase antibody & IL-4: Interleukin 4 \\
IA-2A: Insulinoma associated-2 antibody & IL-10: Interleukin 10 \\
${ }^{*}$ Other missing & TGF- $\beta 1$ : Transforming growth factor-beta 1 \\
FBS: Fasting blood sugar & DQOL: Diabetes Quality of Life \\
2hpp: Two-hour postprandial & SF-36: 36-Item Short Form Survey \\
HbA1c: Glycated hemoglobin & QOL: Quality of life \\
MSC: Mesenchymal stem cell & \\
\hline
\end{tabular}

304 Major complications and death

305 In this study, we did not find any major complications or deaths among participants.

\section{$306 \quad$ Losses and exclusions}

307 Two patients, who received the allocated treatment in the first year and completed the 12 308 months of follow-up, declined to participate in the second course of treatment due to personal 309 issues unrelated to treatment.

\section{Primary outcomes: Safety}

\section{Transplantation-associated adverse events}

312 There were no major transplantation-related adverse events observed in either group. One

313 adverse event potentially unrelated to the MSC transplantation was a mild injection site reaction

314 observed in two patients (one in each group). A grade 3 urticaria was observed in P-1 during 315 the first injection. Symptoms were relieved with the administration of a mild anti-inflammatory 316 medication. A mild increase in lymphocytes occurred in P-2 and mild hyperkalemia in P-4 from 317 the MSC group, both of which occurred 12 months after transplantation and appeared unrelated 318 to the treatment procedure.

319 Other adverse events reported in the MSC and placebo groups were negligible or reported only 320 in the placebo group, mainly without any medical intervention. 
321 Table 2 lists the observed adverse events in this trial. The observed adverse events were not 322 serious, and, when necessary, the required medical interventions were applied.

323 
Table 2. List of observed adverse events. Observed adverse events were not serious, and the required medical considerations were applied in case they needed

\begin{tabular}{|c|c|c|c|c|c|c|c|}
\hline \multirow{2}{*}{ No. } & \multirow{2}{*}{$\begin{array}{c}\text { MedDRA } \\
\text { Code }\end{array}$} & \multirow{2}{*}{ CTCAE term } & \multirow{2}{*}{$\begin{array}{c}\text { Observed } \\
\text { grade }\end{array}$} & \multicolumn{2}{|c|}{ Placebo $(n=10)$} & \multicolumn{2}{|r|}{$\operatorname{MSC}(n=11)$} \\
\hline & & & & $\mathrm{N}$ & Patient ID /time & $\mathrm{N}$ & Patient ID /time \\
\hline \multicolumn{8}{|c|}{ INVESTIGATIONS } \\
\hline 1 & 10001551 & $\begin{array}{l}\text { Alanine aminotransferase (ALT) } \\
\text { increased }\end{array}$ & 1 & 1 & $\mathrm{P}-11 / \mathrm{M} 6$ & & \\
\hline 2 & 10001675 & $\begin{array}{l}\text { Alkaline phosphatase (ALP) } \\
\text { increased }\end{array}$ & 1 & 4 & $\begin{array}{c}\text { P-3/M6 } \\
\text { P-8/M6, } 12 \\
\text { P-9/M12 }\end{array}$ & 5 & $\begin{array}{c}\text { P-2/M6, 9, } 12 \\
\text { P-6/M6 } \\
\text { P-10/M6 }\end{array}$ \\
\hline 3 & 10003481 & $\begin{array}{l}\text { Aspartate aminotransferase (AST) } \\
\text { increased }\end{array}$ & 1 & 2 & $\begin{array}{l}\mathrm{P}-9 / \mathrm{M} 12 \\
\mathrm{P}-11 / \mathrm{M} 6\end{array}$ & & \\
\hline 4 & 10025258 & Lymphocyte count increased & 2 & & & 1 & $\mathrm{P}-2 / \mathrm{M} 12$ \\
\hline 5 & 10047900 & Weight loss & 1 & 1 & P-18/M6 & & \\
\hline
\end{tabular}

\begin{tabular}{|c|c|c|c|c|c|c|c|}
\hline \multicolumn{8}{|c|}{ GENERAL DISORDERS AND ADMINISTRATION SITE CONDITIONS } \\
\hline 6 & 10016558 & Fever & 1 & 1 & P-18/M1 & & \\
\hline \multirow[b]{2}{*}{7} & \multirow[b]{2}{*}{10022095} & \multirow[b]{2}{*}{ Injection site reaction } & 1 & 1 & P-3/M1 & 1 & P-6/W1 \\
\hline & & & 2 & 1 & $\mathrm{P}-5 / \mathrm{M} 1$ & 1 & P-6/M1 \\
\hline 8 & 10033371 & Pain (epigastric region) & 1 & 1 & $\mathrm{P}-12 / \mathrm{M} 3$ & 1 & $\mathrm{P}-13 / \mathrm{M} 2$ \\
\hline \multicolumn{8}{|c|}{ METABOLISM AND NUTRITION DISORDERS } \\
\hline 9 & 10020587 & Hypercalcemia & 1 & 1 & $\mathrm{P}-7 / \mathrm{M} 12$ & & \\
\hline 10 & 10020647 & Hyperkalemia & 4 & & & 1 & $\mathrm{P}-4 / \mathrm{M} 12$ \\
\hline 11 & 10020907 & Hyperuricemia & 1 & 1 & P-18/M12 & & \\
\hline 12 & 10020949 & Hypocalcemia & 2 & 1 & $\mathrm{P}-12 / \mathrm{M} 12$ & & \\
\hline 14 & 10021018 & Hypokalemia & 1 & 1 & P-14/M6 & & \\
\hline 15 & 10021038 & Hyponatremia & 1 & 2 & $\begin{array}{l}\text { P-3/M12 } \\
\text { P-9/M12 }\end{array}$ & & \\
\hline
\end{tabular}

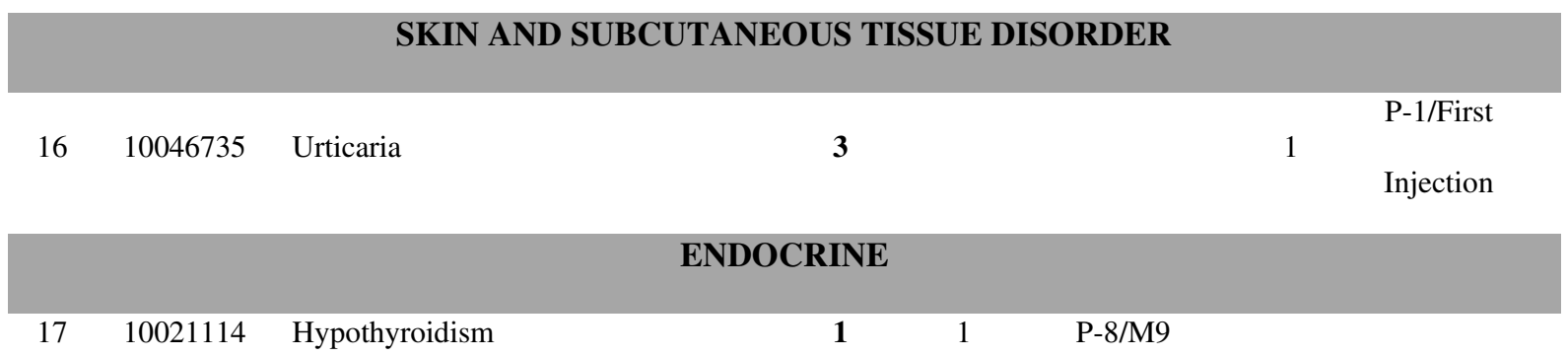


Table 2. List of observed adverse events. Observed adverse events were not serious, and the required medical considerations were applied in case they needed

\begin{tabular}{|c|c|c|c|c|c|}
\hline \multirow{3}{*}{ No. } & MedDRA & \multirow{3}{*}{ CTCAE term } & \multirow{3}{*}{$\begin{array}{c}\text { Observed } \\
\text { grade }\end{array}$} & \multirow[t]{2}{*}{ Placebo $(n=10)$} & \multirow[t]{2}{*}{$\operatorname{MSC}(n=11)$} \\
\hline & \multirow[b]{2}{*}{ Code } & & & & \\
\hline & & & & Patient ID /time & $\mathrm{N} \quad$ Patient ID /time \\
\hline \multicolumn{6}{|c|}{ NEUROLOGY } \\
\hline 18 & 10037175 & Psychiatric disorders & 1 & P-8/M6 & \\
\hline
\end{tabular}

MSC: Mesenchymal stem cell; M: Month; W: Week; N: Number of events

325 A complete list of the assessed adverse events is found in table S1.

326 Hypoglycemia

327 Hypoglycemic events are defined as the observation of blood glucose levels lower than 70

$328 \mathrm{mg} / \mathrm{dl}$. The number of hypoglycemic events was considered not only a safety parameter but also

329 an efficacy outcome. These events are graded from I to $\mathrm{V}$ according to the severity in the

330 CTCAE v.5, as follows: grade I (< lower limit of normal [LLN] - $55 \mathrm{mg} / \mathrm{dL})$; grade II ( $<55-40$

$331 \mathrm{mg} / \mathrm{dL})$; grade III: $(<40-30 \mathrm{mg} / \mathrm{dL})$; grade IV $(<30 \mathrm{mg} / \mathrm{dL}$, life-threatening consequences,

332 seizures); and grade V (Death). The MSC transplantation group had significantly lower

333 numbers of grade I $(\mathrm{P}=0.0457)$ and II $(\mathrm{P}<0.001)$ hypoglycemic episodes and a total number of

334 hypoglycemic events $(\mathrm{P}=0.0164)$ compared to the placebo group (Figure 2a). Early

335 transplantation of MSCs significantly reduced the number of grade II hypoglycemic events 336 compared to late transplantation of MSCs (P=0.008, Figure 2b). 

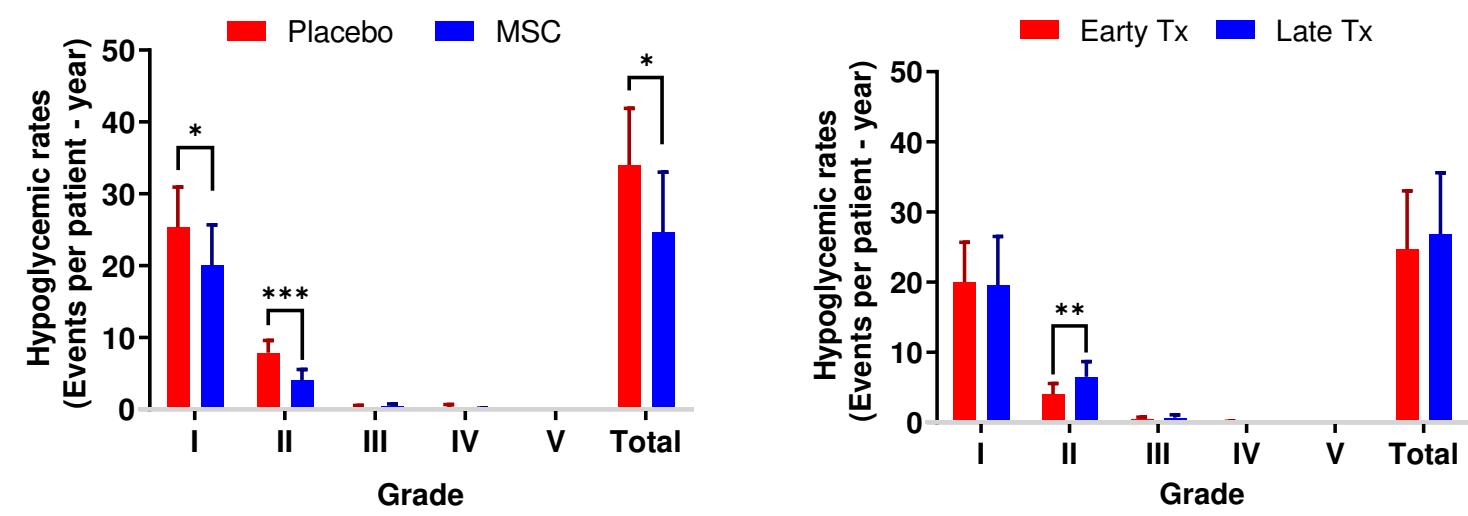

Figure 2. Hypoglycemic rates (events per patient - year) a. Mesenchymal stem cell (MSC) transplantation versus placebo, b. Early versus late transplantation (Grade I: <lower limit of normal (LLN) - 55 mg/dL; Grade II: <55-40 mg/dL; Grade III: <40-30 mg/dL; Grade IV: <30 mg/dL, life-threatening consequences, seizures; Grade V: Death. Error bars represent the standard deviation. $* \mathrm{P}<0.05, * * \mathrm{P}<0.01, * * * \mathrm{P}<0.001)$

Secondary outcome: Efficacy

Mesenchymal stem cells (MSCs) versus placebo

Metabolic indices

341 There were no significant differences in FBS and 2hpp between the MSC and placebo groups

342 (Table S2, Figure 3a, b). As shown in table S2, MSCs significantly reduced the percent of 343 HbA1c 12 months after transplantation $(\mathrm{P}=0.043)$. There were considerable mean changes in 344 HbA1c at month $9(\mathrm{P}=0.061$, Figure $3 \mathrm{c})$. The mean differences in C-peptide levels between the 345 two groups showed higher but insignificant changes that favored MSC transplantation (Figure $3463 \mathrm{~d}$ ). No significant changes in the amount of EI and LI were reported (Figure 3e, f). However, 347 although the 6-month follow-up showed a reduction in EI, there was a slight increase at the 12348 month follow-up (Figure 3e). The LI decreased at the 12-month follow-up in patients who received MSCs (Figure 3f). 
a

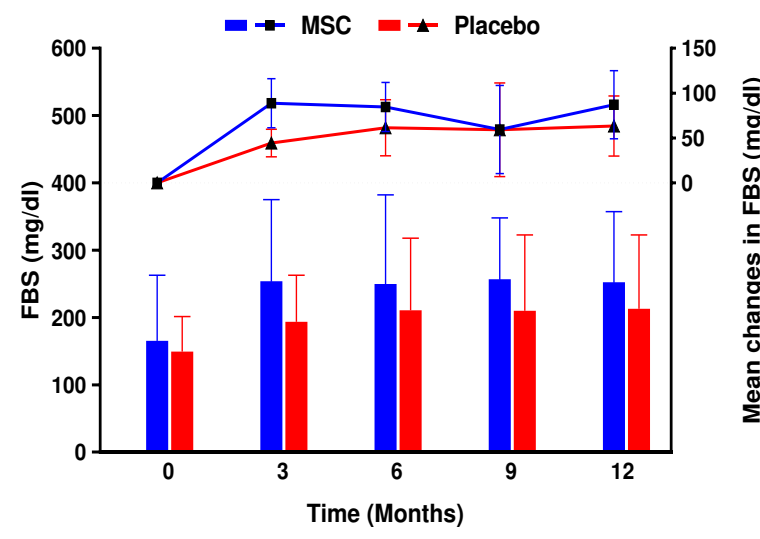

c

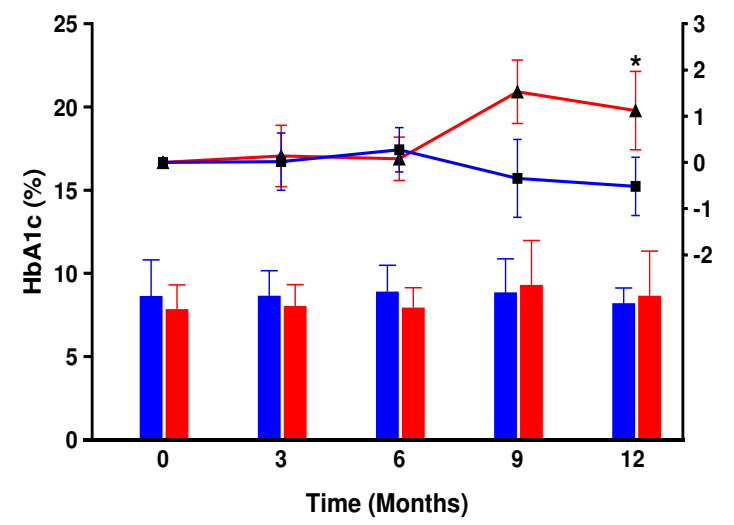

e

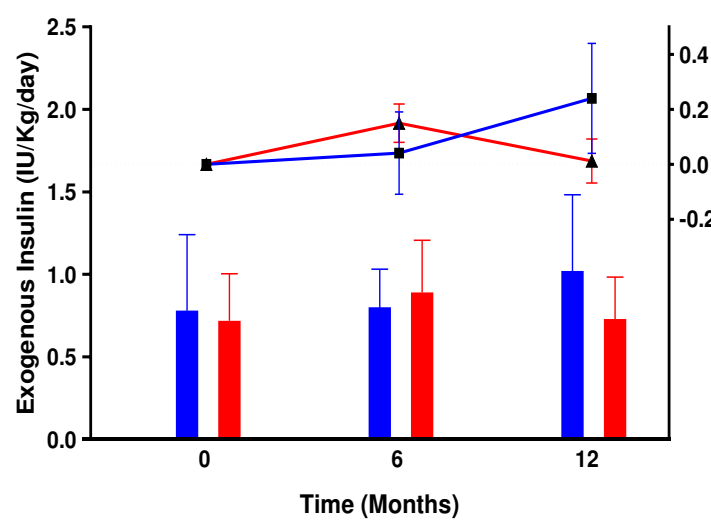

b

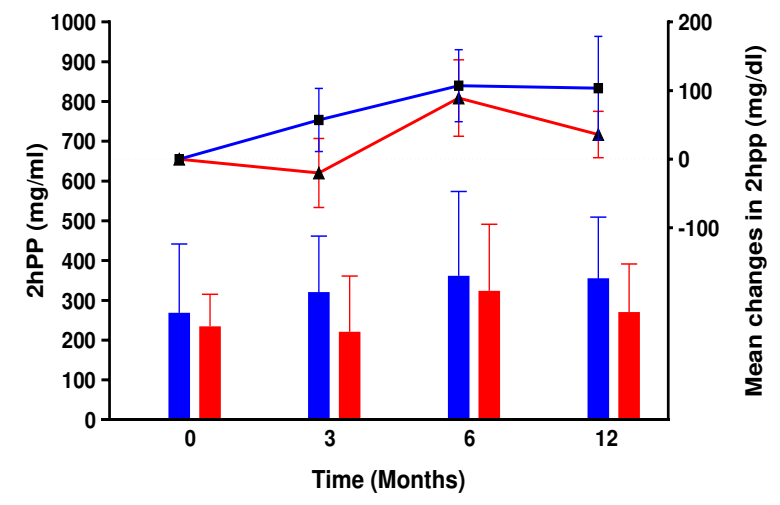

d

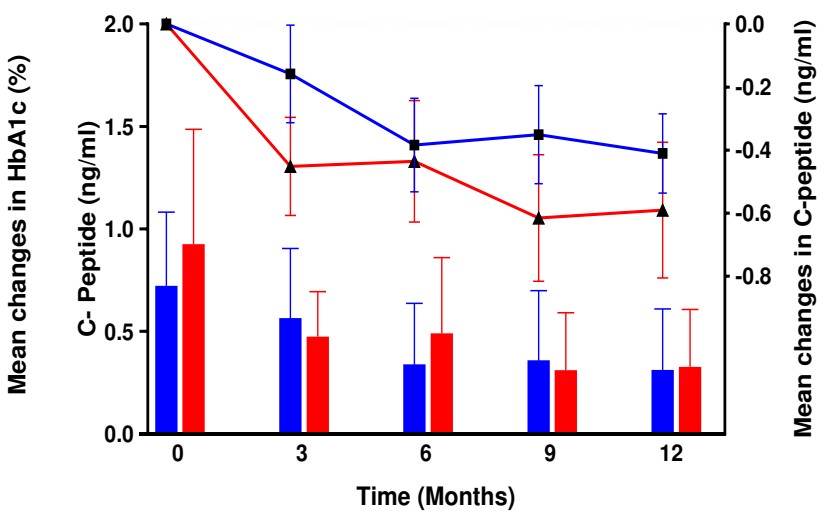

f

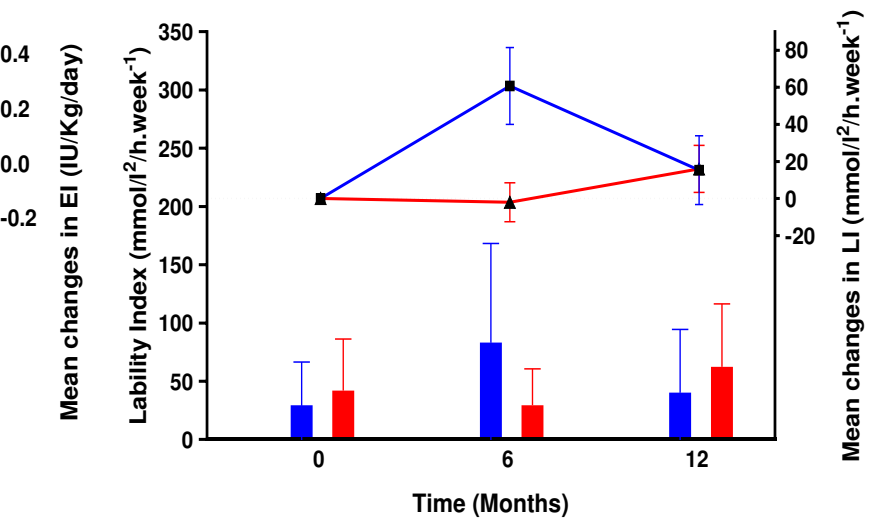

Figure 3. Comparison of metabolic indices between the mesenchymal stem cell (MSC) and placebo groups. The left $\mathrm{Y}$-axis represents the mean in each group drawn by column charts, and the right $\mathrm{Y}$-axis belongs to the mean differences compared to the baseline drawn by scatter plots. a. Fasting blood sugar (FBS), b. Twohour postprandial (2hpp), c. Glycated hemoglobin (HbA1c), d. C-peptide, e. Exogenous insulin (EI), f. Lability 
index (LI). Error bars represent the standard deviation for the bar charts and the standard error of the mean for scatter plots. Chart legend for the entire picture is shown in part a. ${ }^{*} \mathrm{P}<0.05$

Immunologic indices

352 According to previous studies (42, 48), IL-6 and TNF- $\alpha$ have pro-inflammatory effects, whereas

353 IL-4, IL-10, and TGF- $\beta 1$ show anti-inflammatory effects. Transplantation of MSCs, as an 354 immunomodulator, significantly increased the anti-inflammatory cytokines IL-4 $(\mathrm{P}=0.032)$ and 355 IL-10 ( $\mathrm{P}=0.30)$. This effect surprisingly persisted after 12 months (Figure 4c, d; Table S3). 356 TNF- $\alpha$ levels significantly reduced after six months $(\mathrm{P}=0.027)$ and showed a considerable 357 decrease after 12 months (Figure 4b, Table S3).

$358 \mathrm{~T}$ reg cells are a group of immune cells that play an essential role in peripheral tolerance 359 induction and maintenance; therefore, they modulate the immune response and prevent 360 autoimmunity. Flow cytometry analysis of their antigens showed significant increases in $\mathrm{T}$ reg 361 cell levels $(\mathrm{P}=0.0088)$ and Forkhead box $\mathrm{P} 3(\mathrm{FOXP})$ expression $(\mathrm{P}=0.0004) 48$ hours after transplantation of the MSCs (Figure 4f). 


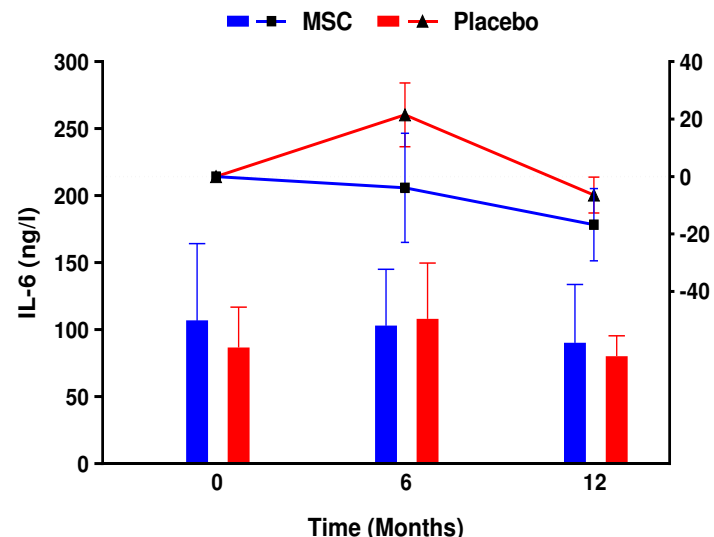

c

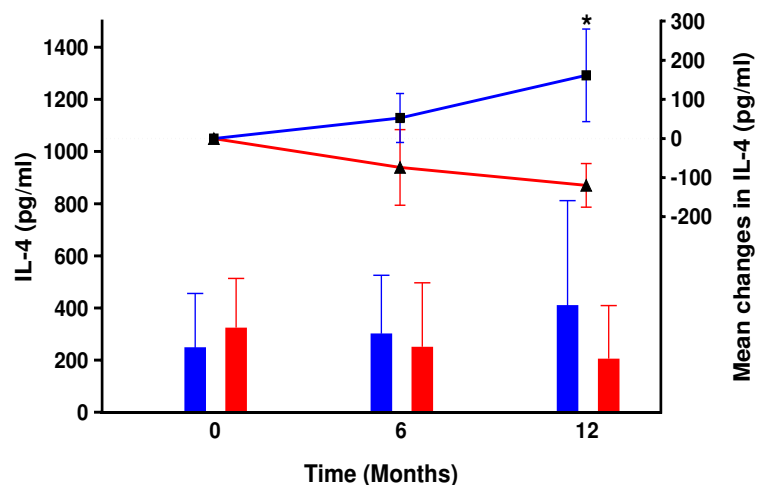

$\mathbf{e}$

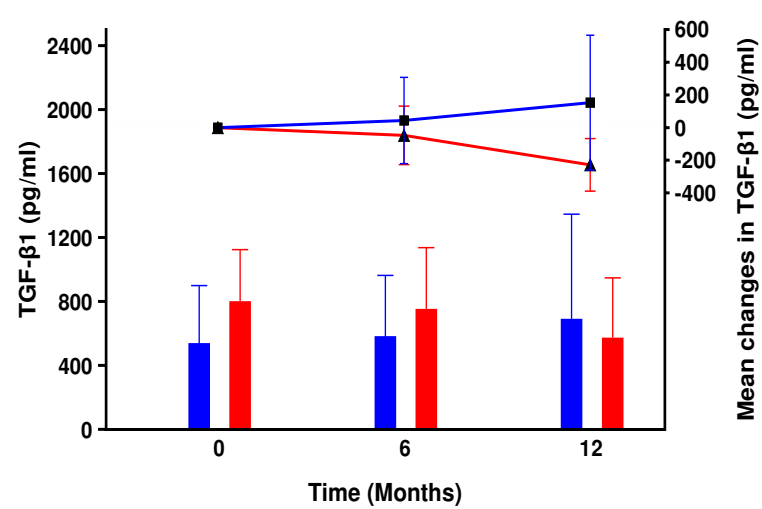

b

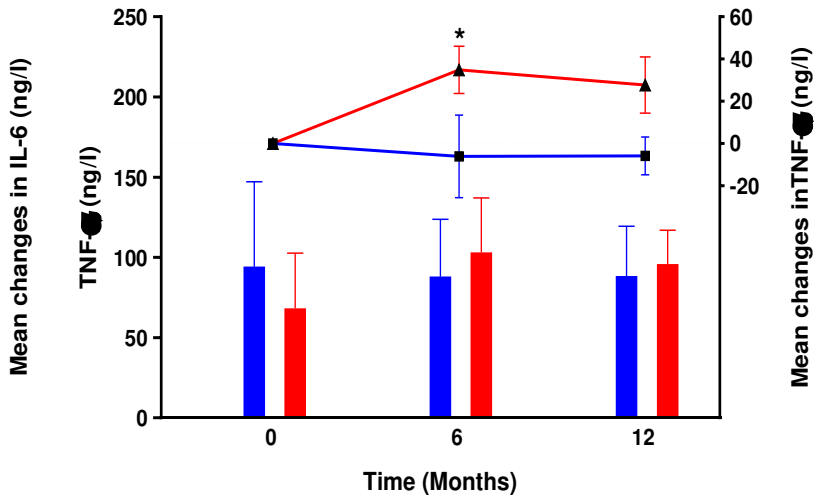

d

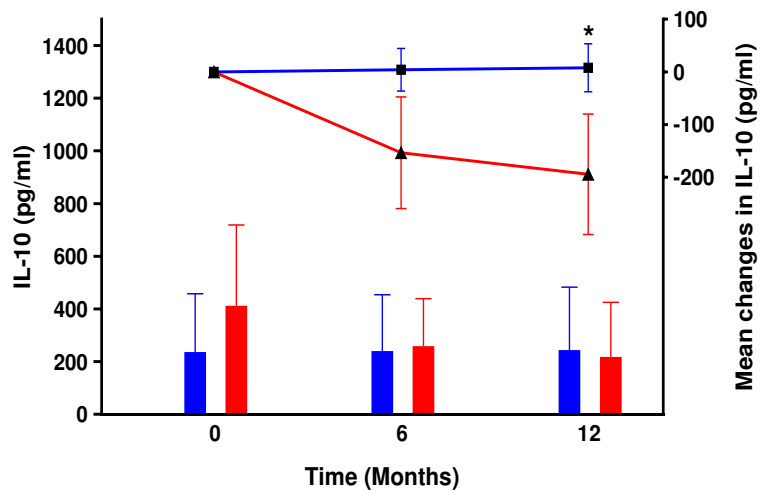

f

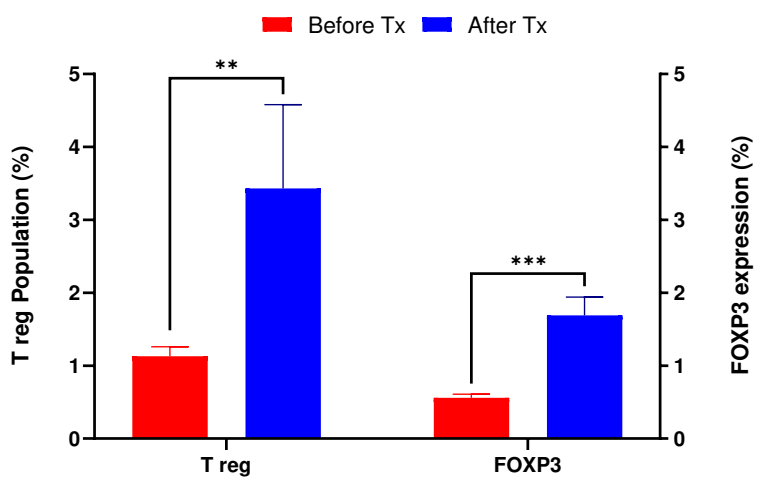

Figure 4. Comparison of cytokine levels between mesenchymal stem cell (MSC) and placebo groups. The left $\mathrm{Y}$-axis represents the mean in each group drawn by column charts, and the right $\mathrm{Y}$-axis belongs to the mean differences compared to the baseline drawn by scatter plots. a. Interleukin 6 (IL-6), b. Tumor necrosis factoralpha (TNF- $\alpha$ ), c. Interleukin 4 (IL-4), d. Interleukin 10 (IL-10), e. Transforming growth factor-beta 1 (TGF- 
B1), f. Regulatory T cell (T reg) population and Forkhead box P3 (FOXP3) expression before and 48 hours after transplantation. Tx: Transplantation. Error bars represent the standard deviation for bar charts and the standard error of the mean for scatter plots. Chart legend for the entire picture is shown in part a unless otherwise indicated. $* \mathrm{P}<0.05, * * \mathrm{P}<0.01, * * * \mathrm{P}<0.001$

363

364

\section{Quality of Life (QOL)}

DQOL questions are categorized into three subsections: satisfaction, impact, and worry. The SF-36 questions are categorized into eight subsections: physical functioning (PF), role physical (RP), bodily pain (BP), general health (GH), vitality (VT), social functioning (SF), role - emotional (RE), and mental health (MH). Two main sections of the SF-36 consist of these eight subsections. Section A: Physical Health includes the PF, RP, BP, GH, and VT subsections, whereas section B: Mental Health includes the GH, VT, SF, RE, and MH subsections.

After six months, patients reported a significant reduction in worry related to DQOL in the MSC group ( $\mathrm{P}=0.012)$. The MSC group reported a significant improvement in $\mathrm{RP}(\mathrm{P}=0.020)$ at the 6-month follow-up and a significant improvement in $\mathrm{GH}(\mathrm{P}=0.037)$ at the 12 -month followup (Table S4, Figure 5a).

$\mathbf{a}$

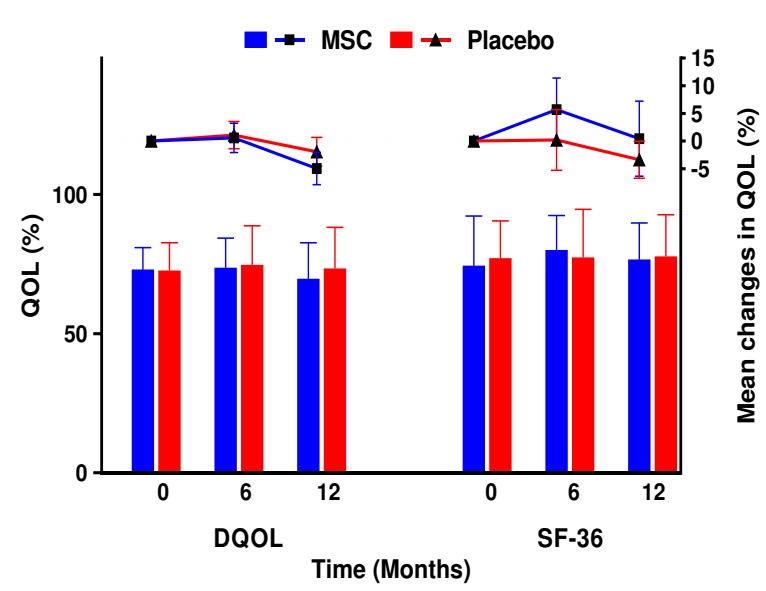

b

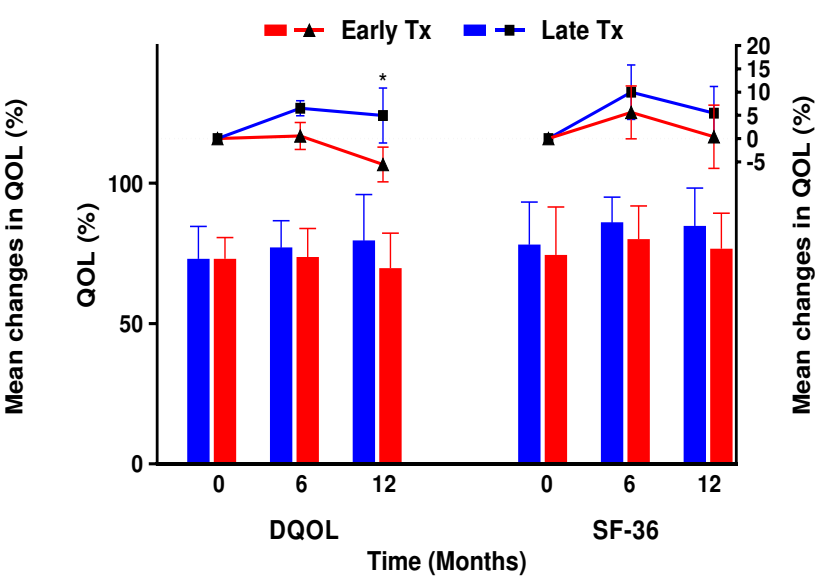

Figure 5. Quality of life (QOL) a. Comparison of patients' QOL between the mesenchymal stem cell (MSC) and placebo groups based on the Diabetes specific QOL (DQOL) and 36-Item Short Form Survey (SF-36) 
questionnaires. The left $\mathrm{Y}$-axis represents the mean in each group drawn by column charts, and the right $\mathrm{Y}$-axis belongs to the mean differences compared to the baseline drawn by scatter plots. There were no significant changes reported. Error bars represent the standard deviation for bar charts and the standard error of the mean for scatter plots. b. Comparison of patients' QOL between early (Early Tx) and late (Late Tx) transplantation of MSCs based on the DQOL and SF-36 questionnaires. The left Y-axis represents the mean in each group drawn by column charts, and the right $\mathrm{Y}$-axis belongs to the mean differences compared to the baseline drawn by scatter plots. Error bars represent the standard deviation for bar charts and the standard error of the mean for scatter plots. $* \mathrm{P}<0.05$

Early versus late transplantation

Quality of life (QOL)

Table S5 shows that the total DQOL $(\mathrm{P}=0.026)$ and social functioning subsection $(\mathrm{P}=0.025)$ of the SF-36 questionnaire showed significant improvements in the Late Tx group at 12 months follow-up (Figure 5b).

Metabolic indices

We compared the new-onset group that received MSC transplantation in the first year when they were newly diagnosed with T1D (Early Tx) and the patients who received the transplantation at least one year after their diagnosis (Late Tx). Table S6 shows that early transplantation of MSCs can significantly decrease the percentages of HbA1c at $3(\mathrm{P}<0.001), 6$ $(\mathrm{P}=0.015)$, and $12(\mathrm{P}=0.041)$ months after transplantation compared to the Late $\mathrm{Tx}$ group

388 (Figure 6c). Serum C-peptide levels in the Early Tx group were significantly higher than the 


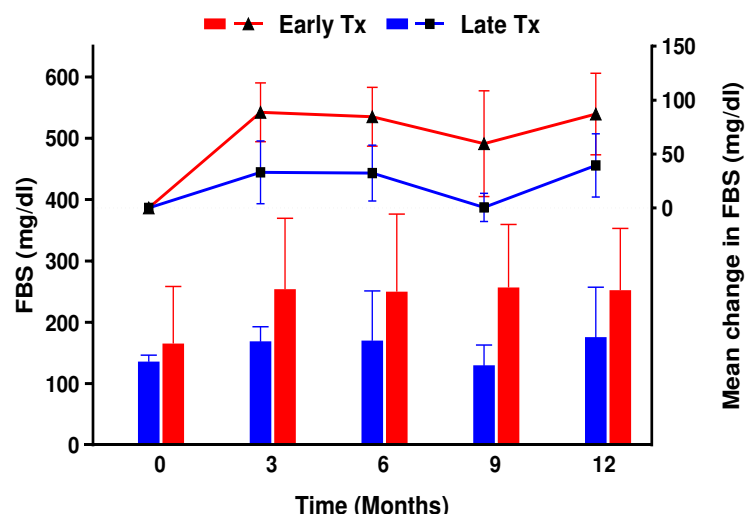

c

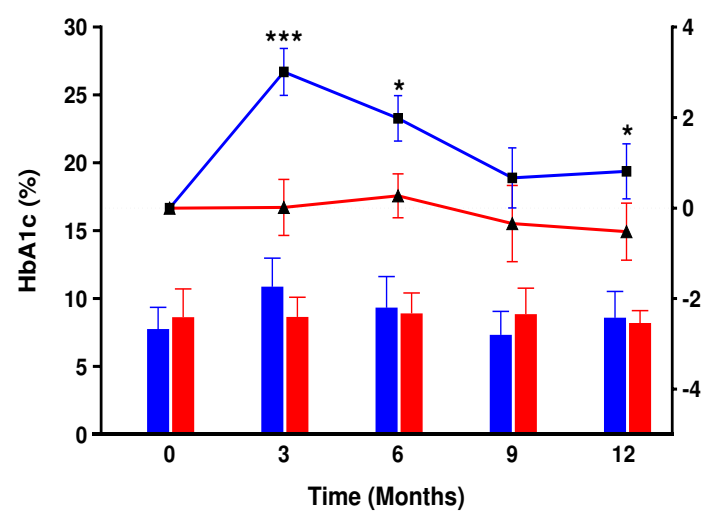

e

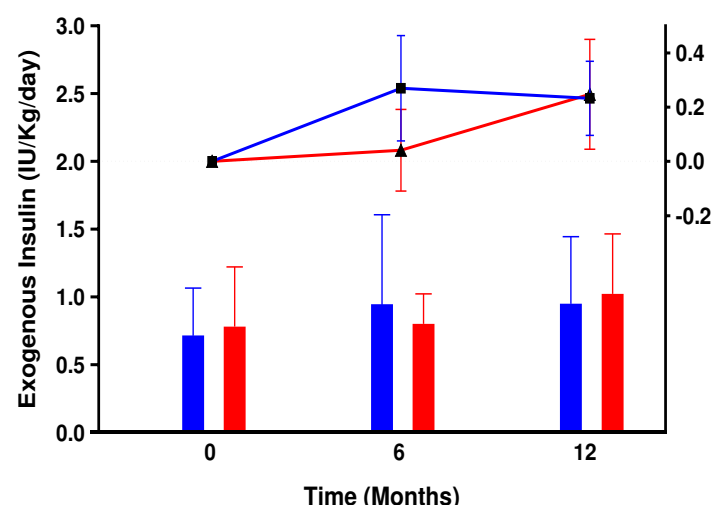

b

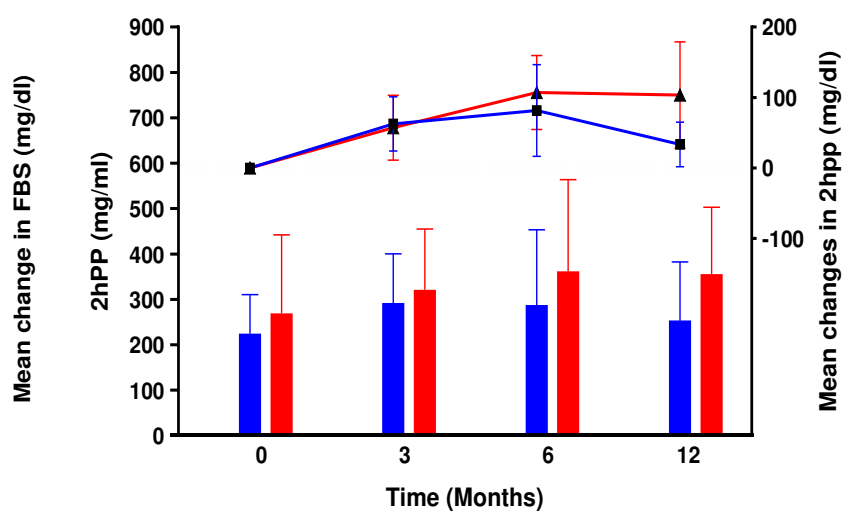

d

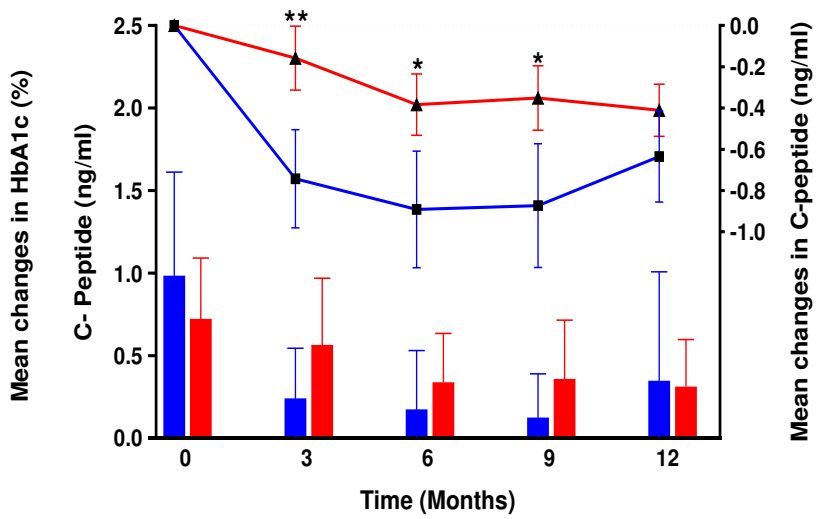

f

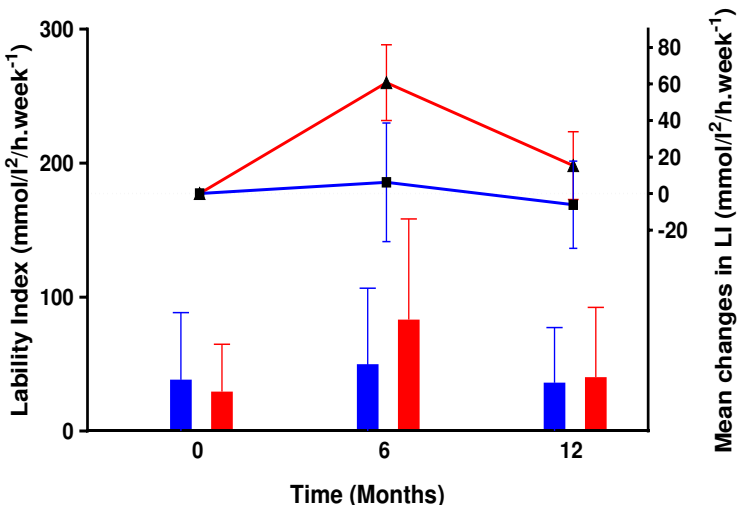

Figure 6. Comparison of metabolic indices between early transplantation (Early Tx) and late transplantation (Late Tx) groups. The left Y-axis represents the mean in each group drawn by column charts, and the right $\mathrm{Y}$-axis belongs to the mean differences compared to the baseline drawn by scatter plots. a. Fasting blood sugar (FBS), b. Two-hour postprandial (2hpp), c. Glycated hemoglobin (HbA1c), d. C-peptide, e. 
Exogenous insulin (EI), f. Lability index (LI). Error bars represent the standard deviation for bar charts and the standard error of the mean for scatter plots. Chart legend for the entire picture is shown in part a. $* \mathrm{P}<0.05$, $* * \mathrm{P}<0.01, * * * \mathrm{P}<0.001$

$391 \quad$ Immunologic indices

392 TNF- $\alpha$ levels were significantly lower in the Early Tx group than the Late Tx group at the 6$393(\mathrm{P}=0.002)$ and 12- $(\mathrm{P}=0.028)$ month follow-ups. IL-6 levels were not significantly different 394 between the groups ( $\mathrm{P}=0.877$ ) (Table S7, Figure 7a, b). IL-4 and IL-10 levels were significantly 395 higher in the Early Tx group compared to the Late Tx group at the 6- and 12-month follow-ups $396\left(\mathrm{P}_{6}=0.025, \mathrm{P}_{12}=0.001\right.$, and $\mathrm{P}_{6}<0.001, \mathrm{P}_{12}<0.001$, respectively) (Table $\mathrm{S} 7$, Figure $\left.7 \mathrm{c}, \mathrm{d}\right)$. TGF$397 \quad \beta 1$ levels were significantly higher in the Early Tx group than the Late Tx group at the 6-month $398(\mathrm{P}=0.038)$ and 12-month $(\mathrm{P}=0.016)$ follow-ups (Table $\mathrm{S} 7$, Figure 7e), which indicated a 399 successful shift from pro-inflammatory to anti-inflammatory cytokines following MSC 400 transplantation in newly diagnosed T1D patients. 


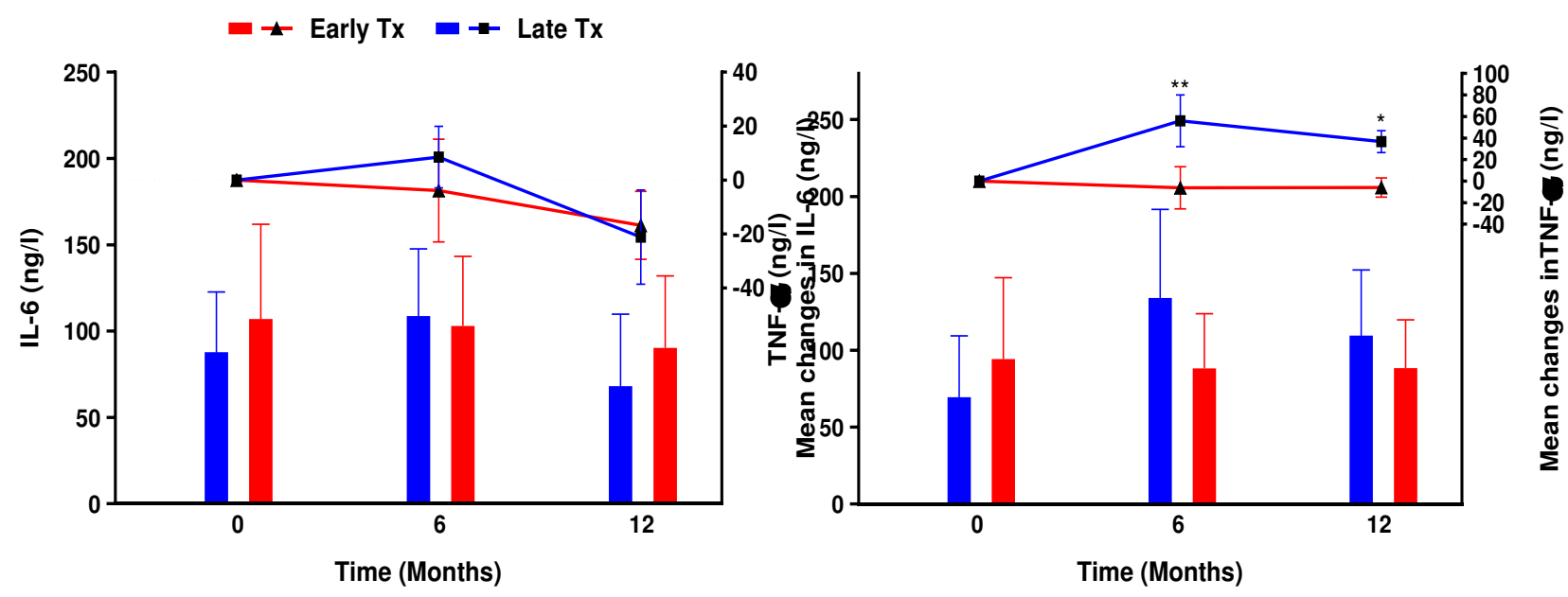

c

d

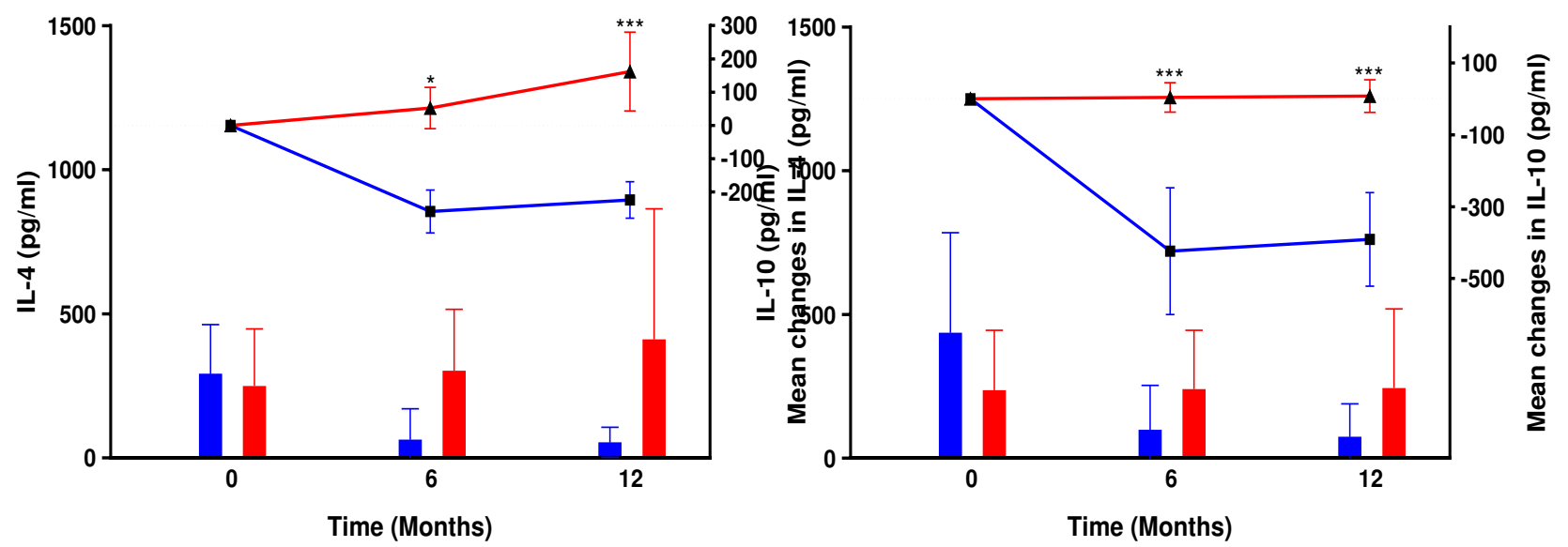

e

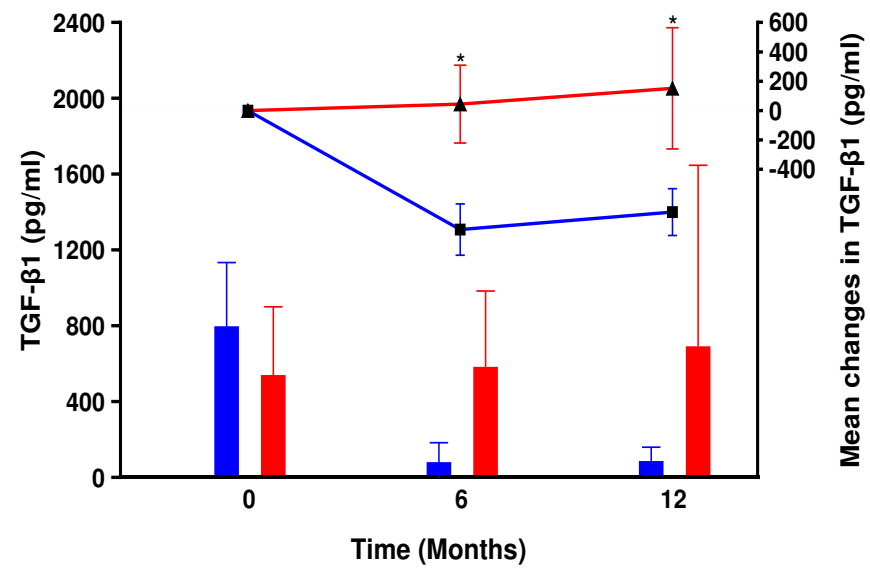


Figure 7. Comparison of cytokine levels between the early transplantation (Early Tx) and late transplantation (Late Tx) groups. The left Y-axis represents the mean in each group drawn by column charts, and the right $\mathrm{Y}$-axis belongs to the mean differences compared to the baseline drawn by scatter plots. a. Interleukin 6 (IL-6), b. Tumor necrosis factor-alpha (TNF- $\alpha$ ), c. Interleukin 4 (IL-4), d. Interleukin 10 (IL-10), e. Transforming growth factor-beta 1 (TGF- $\beta 1$ ). Error bars represent the standard deviation for bar charts and the standard error of the mean for scatter plots. Chart legend for the entire picture is shown in part a. $* \mathrm{P}<0.05$, $* * \mathrm{P}<0.01, * * * \mathrm{P}<0.001$

\section{Exercise}

403

ADA guidelines recommend that children 5 to 18 years of age exercise at least three days each week, with more than 60 minutes of daily activity and 150 minutes of weekly exercise for adults $(5,49)$. This study measured the metabolic and immunologic indices by considering the 3.5 hours per week exercise cut-off for some patients.

The percentage of HbA1c in patients who received MSCs and exercised more than the cut-off mentioned above (in figures shown by "Yes") was significantly lower than those who received MSCs or placebo and did not exercise (in figures shown by "No") based on ADA recommendations $(\mathrm{P}=0.0035, \mathrm{P}=0.0033$, respectively, Figure $8 \mathrm{c})$. HbA1c levels in patients who received MSCs and who had adequate exercise levels were significantly lower than the placebo group, who had adequate levels of exercise $(\mathrm{P}=0.0117$, Figure $8 \mathrm{c})$.

As shown in Figure 8b, exercise significantly increased the serum C-peptide level of patients who received the placebo and had adequate levels of exercise (Yes, Placebo) compared to the patients who received placebo and exercised less than the recommendations (No, Placebo) ( $\mathrm{P}=0.0088)$. Moreover, patients in the MSC group who had adequate exercise levels (Yes, MSC group) had significantly higher C-peptide levels than the placebo group who exercised less (No, Placebo group). The No, MSC group had higher C-peptide levels compared to the No, Placebo group $(\mathrm{P}=0.0016,0.0019$, respectively, Figure $8 \mathrm{~d})$. 
420 IL-10 was significantly higher in patients who received MSC than the placebo group, regardless 421 of the level of exercise (Yes, MSC vs. Yes, Placebo: P=0.0156; Yes, MSC vs. No, Placebo: $422 \mathrm{P}=0.0228$; No, MSC vs. Yes, Placebo: $\mathrm{P}=0.0070$; No, MSC vs. No, Placebo: $\mathrm{P}=0.0097$; Figure 423 8j). The No, MSC group had significantly higher TGF- $\beta 1$ levels compared to the Yes, Placebo 424 group $(\mathrm{P}=0.0438$, Figure 8k). All other changes were not significant (Figure 8a, b, e-i). 
a

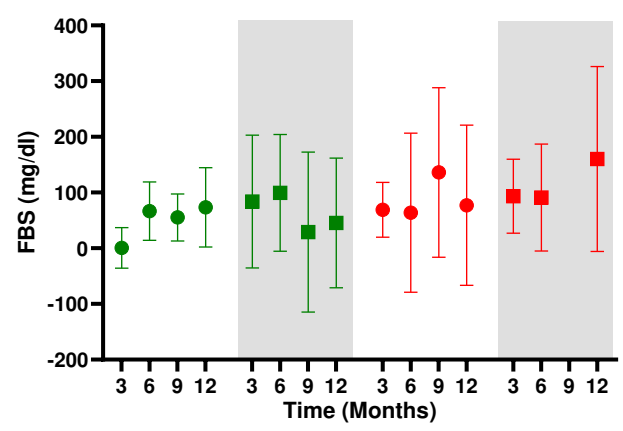

c

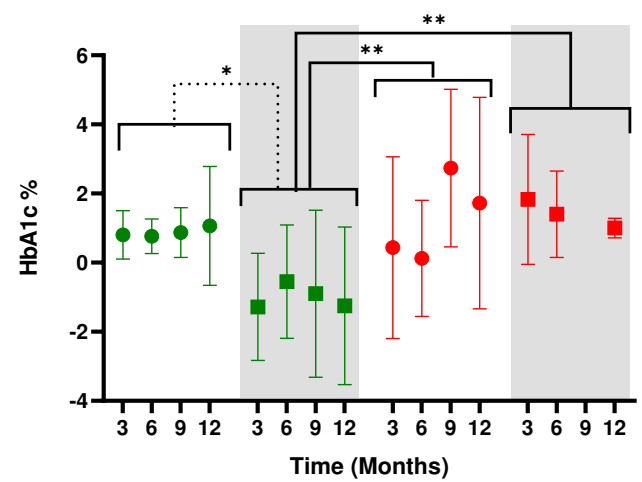

e

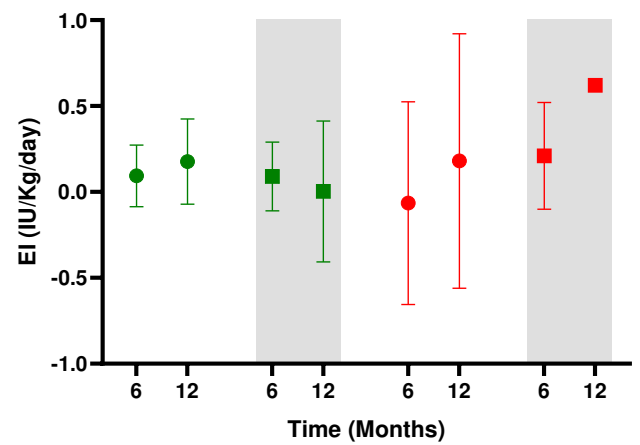

g b

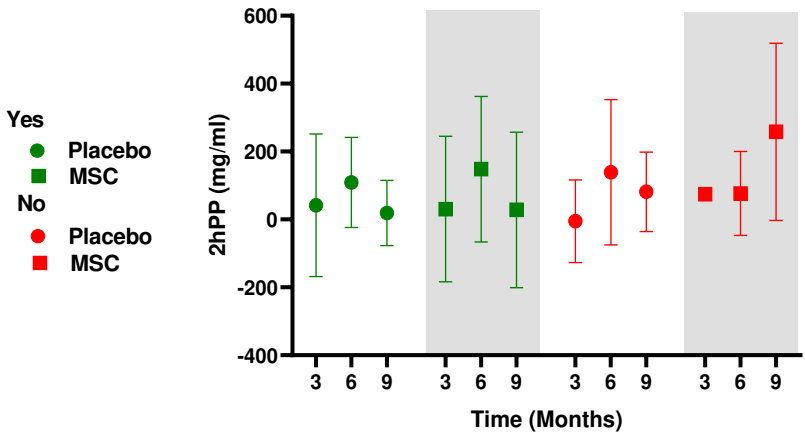

d

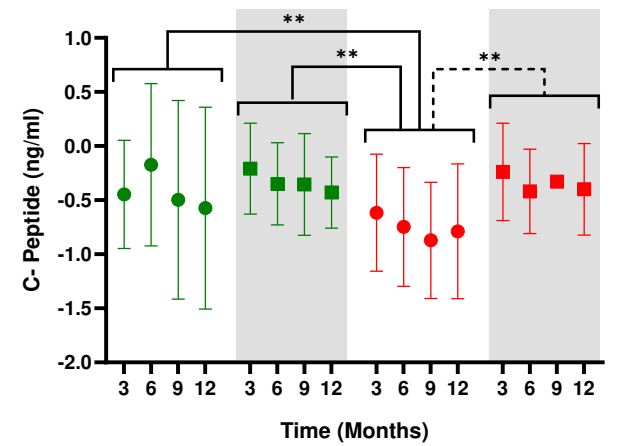

f

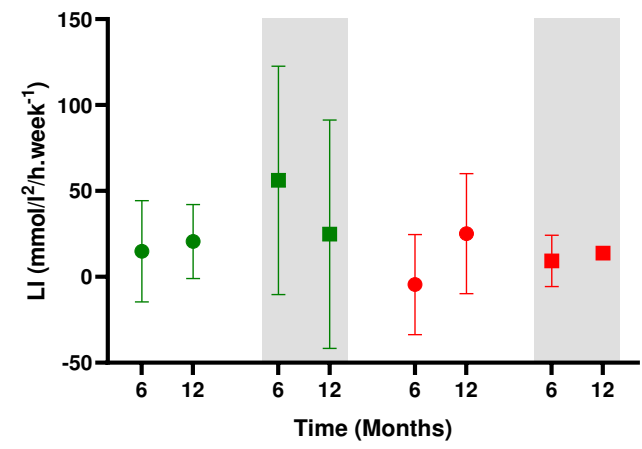

h 


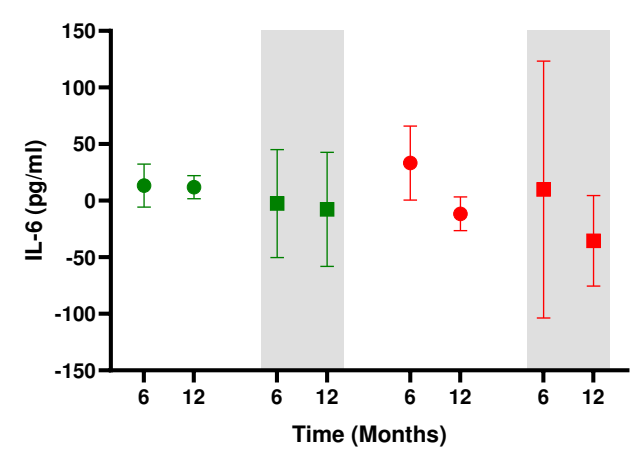

i

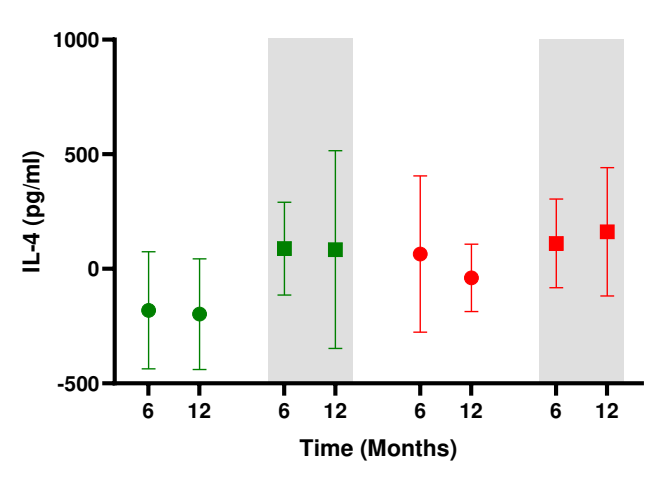

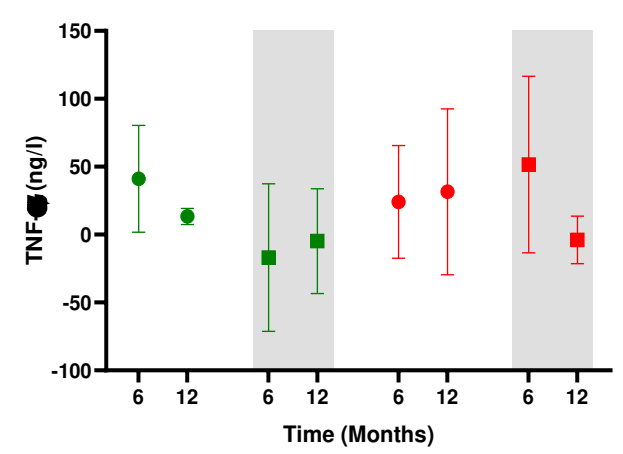

$\mathbf{j}$

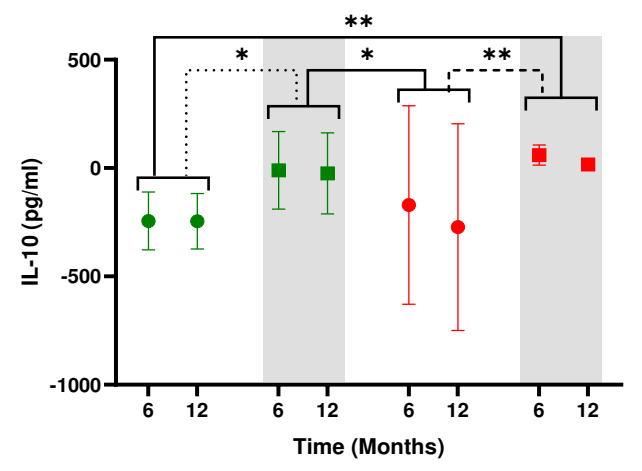

$\mathbf{k}$

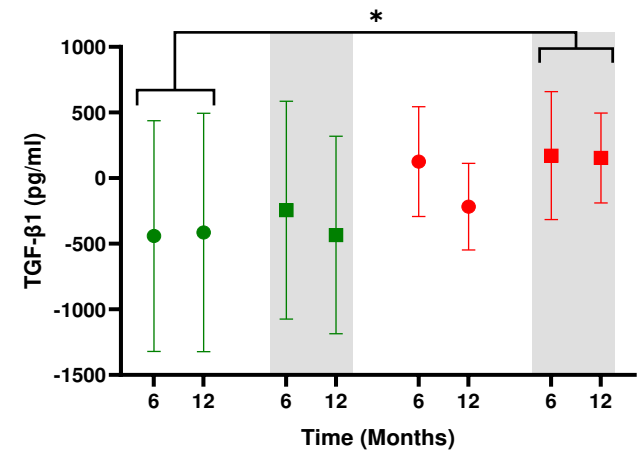

Figure 8. Comparison of metabolic indices and cytokine levels in the mesenchymal stem cell (MSC) and placebo groups based on patient exercise. a. Fasting blood sugar (FBS), b. Two-hour postprandial (2hpp), c. Glycated hemoglobin (HbA1c), d. C-peptide, e. Exogenous insulin (EI), f. Lability index (LI), g. Interleukin 6 (IL-6), h. Tumor necrosis factor-alpha (TNF- $\alpha$ ), i. Interleukin 4 (IL-4), j. Interleukin 10 (IL-10), k. Transforming growth factor-beta 1 (TGF- $\beta 1$ ). Data are presented as mean \pm standard deviation with an exercise cut-off of $3.5 \mathrm{~h} /$ week. Yes, means more exercise than the cut-off. No, means less exercise than the cut-off. Chart legend for the entire picture is shown in part a. ${ }^{*} \mathrm{P}<0.05, * * \mathrm{P}<0.01$ 


\section{Discussion}

427 To the best of our knowledge, this is the first randomized triple-blinded, placebo-controlled clinical trial that assesses the safety and efficacy of transplanting autologous bone marrowderived MSCs as treatment of newly diagnosed T1D patients.

430 Our results showed that transplantation of bone marrow-derived MSCs in diabetic children is 431 safe and well-tolerated over the study follow-up period. We followed the safety indices for 24 432 months and found that this procedure's long-term safety was acceptable (data are not shown). 433 There were no major complications and transplantation-associated adverse events reported, 434 supported by previous studies harboring MSC transplantations for various diseases (50-60).

435 Interestingly, we observed that the MSC transplantation could significantly reduce the number 436 of hypoglycemic events in recipients as a major life-threatening complication of T1D in 437 children. This effect was reported in a preclinical study of MSC transplantation for post438 hepatectomy liver failure (61). Additionally, for the first time, we showed that early 439 transplantation of MSCs significantly reduced the rate of grade II hypoglycemic events in T1D 440 patients compared to late transplantation of MSCs.

441 The efficacy of MSC transplantation in our study was favorable. We observed a significant 442 reduction of $\mathrm{HbA} 1 \mathrm{c}$ at month 12 along with its considerable reduction in month 9 . There were 443 higher, but not significant, serum C-peptide levels, a significant increase in serum levels of IL4444 and IL-10, and a slight increase in TGF- $\beta 1$ after 12 months as anti-inflammatory cytokines. 445 Besides, there was a significant reduction in serum TNF- $\alpha$ at month 6 and a considerable 446 reduction at month 12, along with a moderate decrease in IL-6 levels at 12 months, as pro447 inflammatory cytokines. Previous studies showed a decreased level of IL-4 in newly diagnosed 448 T1D patients (62). We showed that MSCs could increase serum IL-4 levels. The anti449 inflammatory properties of IL-4 might prevent disease progression. We did not observe any 450 significant differences in FBS levels between the groups, which was confirmed by previous 
studies likely attributed to fluctuations in FBS levels, which are influenced by many variables $(11)$.

453 Although IL-10 has an anti-inflammatory effect that prevents inflammation as the main 454 pathogenesis of autoimmune disorders, its role in modulating disease progression in T1D is 455 debatable (63). The results of several studies suggest a correlation between elevated IL-10 and 456 disease attenuation (63-65). The proposed mechanism of action for IL-10 mediated T1D 457 regulation includes increasing the numbers of $\mathrm{T}$ reg cells and serum levels of T-helper 2-type cytokines (IL-4 and IL-10) while reducing serum levels of T-helper 1-type cytokines (IL-2 and IFN- $\gamma)(66,67)$

Potential immunosuppressive effects of TGF- $\beta$ are accepted in autoimmune diseases used against most immune cells through the development and peripheral differentiation of Tregs and induced expression of FOXP3 in the context of T1D $(63,68)$.

IL-6 is a pro-inflammatory cytokine that plays a role in autoimmune disease progression. The results of preclinical studies report a correlation between IL-6 production and $\beta$-cell destruction $(63,69,70)$. Chen et al. conducted a systematic review and concluded that a link existed

466 between serum IL-6 levels and T1D (71). An ongoing clinical trial aims to preserve $\beta$ cells 467 through an IL-6 blockade by tocilizumab administration (NCT02293837).

468 TNF- $\alpha$ is a pro-inflammatory cytokine produced by dendritic cells and macrophages; its effects on MHC-I upregulation results in accelerating $\beta$-cell death and initiation of T1D $(72,73)$.

470 Mastrandrea et al., in a randomized pilot study, have reported preservation of $\beta$-cell function in 471 newly diagnosed T1D patients who received TNF blockers (74).

472 Of note is an increase in anti-inflammatory cytokines (TGF- $\beta$, IL-4, and IL-10) and a decrease 473 in pro-inflammatory cytokines (TNF- $\alpha$ and IL-6) with the promotion of T reg cells, which has 474 been reported in other studies as some of the immunomodulatory functions of MSCs. These 475 findings align with our results $(13,36,39,42,45,48,75-77)$. 
We also observed an improved QOL in the patients in terms of significantly reduced DQOLworry and improved SF36-Role-Physical evaluation at month 6 as well as SF36-General Health at month 12 .

In 2013, Hu et al. conducted a randomized clinical trial to evaluate the effects of Wharton's jelly-derived MSC injection in 29 new-onset T1D patients, with 15 patients in the treatment group and 14 patients in the control group. They observed higher C-peptide levels and improved glycemic control after two years of follow-up (11). Carlsson et al. reported that systemic injection of autologous bone marrow-derived MSCs in 9 patients compared to a control group could preserve or even increase C-peptide levels in response to a mixed-meal tolerance test (MMTT) during the first year (54). Our data support the results of these studies.

The results of some studies showed that hyperglycemia is caused by reduced $\beta$-cell mass and $\beta$-cell dysfunction. Its extent varies between patients and is based on patient age and level of insulitis. More than $80 \%$ loss of beta-cell mass at the onset of T1D is a common finding in studies related to T1D pathogenesis, which suggested a preserved $\beta$-cell mass with up to $20 \%$ residual insulin-secreting cells. Some researchers have stated that $\beta$-cell mass might be underestimated due to insulin degranulation, which occurs in exhausted $\beta$ cells $(78,79)$.

492 From this point of view, we evaluated the efficiency of early versus late transplantation of MSCs following the occurrence of the first clinical symptoms of T1D, in addition to comparing 494 MSC and placebo groups.

495 We found that early transplantation of MSCs in newly diagnosed patients had benefits 496 compared to late transplantation. These benefits included a significant decrease in HbA1c at 497 months 3, 6, and 12; significantly higher C-peptide levels at months 3, 6, and 9; significantly 498 lower level of TNF- $\alpha$ at 12 months and slightly lower level of IL-6 at month 6 as pro499 inflammatory cytokines. There were significant increases in the anti-inflammatory cytokines 500 IL-4, IL-10, and TGF- $\beta 1$ at 12 months. We also observed significantly reduced QOL in terms 

passed from the onset of diabetes in the Late Tx group. The patients were more adapted to their disease situation and more stable than newly diagnosed patients.

Another factor that affected blood glucose management in T1D patients is the activity level.

Regular exercise should be encouraged in people with insulin-dependent diabetes to decrease

506 cardiovascular disease risk and improve QOL. In addition, mild exercise increases insulin action without influencing BMI. Although physical exercise should be undertaken in T1D patients with safety recommendations for blood glucose monitoring before and after exercise to prevent hypoglycemia or hyperglycemia, this challenge could be mostly overcome with a regular, anticipated exercise program $(80,81)$.

511 We found that more than $3.5 \mathrm{~h}$ /week of exercise in addition to MSC transplantation could

512 significantly decrease $\mathrm{HbA1c}$ levels and increase C-peptide and Il-10 levels when compared to patients who did not have enough exercise and received the placebo. Furthermore, the effects of the MSC transplantation are superior to exercise alone since patients who did not have 515 enough exercise but received MSC transplantation had significantly higher levels of TGF- $\beta 1$ 516 and IL-10 compared to the placebo group patients who had enough exercise.

517 This study had several limitations. First, a limited number of patients met the defined eligibility 518 criteria that caused a longer than expected recruitment process. T1D is a multifactorial disease 519 probably influenced by patients' lifestyle, socioeconomic status, stress level, exercise, diet, and 520 other known and unknown factors that we did not consider. Thus, some studies are needed to 521 assess the effects of these factors on disease progression. International Society for Pediatric and

522 Adolescent Diabetes (ISPAD) noted the importance of partial remission in the early stages of 523 type-1 diabetes following insulin treatment initiation, known as the honeymoon phase. This period reflects the partial recovery of $\beta$-cell with increased insulin secretion, in which the metabolic indices, notably $\mathrm{HbA1c}$ and C-peptide, could improve towards near normoglycemia 
condition $(82,83)$. In this study, since all participants were enrolled in their early stage of diagnosis, their condition could be affected by the honeymoon phase, which could have obscured the MSC's effects. Finally, regarding the possible reduced therapeutic potential of diabetics' MSCs, further evaluation should be considered for allogeneic MSCs transplantation. In this study, we found that transplantation of MSCs in T1D patients is safe and tolerable during the follow-up period. MSC transplantation can improve some of the patients' metabolic indices and modulate their immune responses. Early transplantation of MSCs can greatly improve metabolic indices and alleviate immune responses by increasing anti-inflammatory cytokines and decreasing pro-inflammatory cytokines compared to late transplantation of MSCs. We observed a noticeable pro-inflammatory to anti-inflammatory cytokine shift in addition to an 536 increased $\mathrm{T}$ reg cell population, which provided additional evidence for the benefits of early 537 transplantation of MSCs. However, a detailed study with different cell doses and repeated 538 injections is required to achieve superior clinical results.

539 Although it was hard to control lifestyle variables in patients, we recommended that all study 540 participants exercise by considering safety concerns, resulting in enhanced glycemic control in 541 a limited number of patients who exercised more than $3.5 \mathrm{~h} / \mathrm{week}$. Therefore, controlling 542 patients' lifestyles in addition to MSC transplantation could improve patients' responses to 543 therapy, which should be evaluated in a greater number of participants.

544 A phase III study with a higher number of patients who receive multiple doses of MSC 545 injections and longer follow-ups are needed to elucidate the therapeutic effects of MSCs in T1D 546 and shed light on its molecular mechanisms and pathways behind this process.

547 We conclude that autologous bone marrow-derived MSC transplantation is a safe therapeutic 548 choice for newly diagnosed labile T1D patients who have high blood glucose fluctuations and 549 experience several episodes of hypoglycemia. 


\section{Declarations}

\section{Ethics approval and consent to participate}

553 The Research Ethics Committee at Royan Institute approved this study (approval code: 554 IR.ACECR.ROYAN.REC.1394.50), and the study was conducted under the Declaration of 555 Helsinki. All participants or their parents or legal guardians (when required for pediatric 556 participants) received comprehensive oral and written information about the nature and possible 557 consequences of the study. They signed a written informed consent form before participating 558 in this clinical trial.

\section{Consent for publication}

560 Not applicable.

\section{$561 \quad$ Availability of data}

562 The data that supports the findings of this study are available in the supplementary material of 563 this article.

\section{Competing interest}

565 none

\section{Funding}

567 This work was financially supported by Royan Institute [code: 94000019]; and the Iranian Vice-

568 Presidency for Science and Technology, Council for Development of Stem Cell Sciences and 569 Technologies [grant number: REP-441].

570 Author contributions

571 MI: Conceptualization, Methodology, Investigation, Resources, Data Curation, Visualization,

572 Writing - Original Draft; ASH: Conceptualization, Methodology, Investigation, Resources, 573 Data Curation, Visualization, Writing - Original Draft; MM: Conceptualization, Methodology, 574 Investigation, Resources, Data Curation, Visualization, Writing - Original Draft; SM: Formal 575 analysis, Data Curation; AR: Supervision, Resources, Project administration; FK: 576 Investigation; AAHA: Investigation; FA: Investigation; NJ: Investigation; MAMM: 
577 Investigation; AS: Investigation, Resources; FA: Investigation, Resources; SEH: Investigation;

578 FMN: Investigation; RSY: Investigation; RN: Investigation; EHS: Conceptualization,

579 Resources, Supervision, Methodology, Validation, Funding acquisition, Project administration,

580 Writing - Review \& Editing; HB: Conceptualization, Supervision, Methodology, Funding

581 acquisition, Writing - Review \& Editing. All authors read and approved the final manuscript.

\section{Acknowledgments}

583 The special thank goes to participating individuals and their families for their patience and 584 endurance. We would also like to thank the Children's Growth and Development Research 585 Center for their support. M.I., A.S., and M.M. contributed equally to this work as first authors.

\section{Registration of clinical trial}

The trial was registered at the Iranian Registry of Clinical Trials (IRCT) with the identifier IRCT ID: IRCT2016070428786N1(84) and at the U.S. National Institutes of Health

589 (ClinicalTrials.gov) with the related identifier NCT04078308 (85).

\section{Supplementary materials}

Table S1. Complete List of assessed Adverse Events

Table S2. Comparison of metabolic indices in a 12-month follow-up of mesenchymal stem

594 cells (MSCs) versus placebo

595 Table S3. Comparison of immunologic indices in 12 months follow-up of MSCs versus placebo

596 Table S4. Comparing the quality of life (QOL) questionnaires scores in 12 months follow-up 597 of MSCs versus Placebo

598 Table S5. Comparison of quality of life (QOL) questionnaire scores in 12 months of follow-up 599 between the early (Early Tx) and late (Late Tx) transplantation groups

600 Table S6. Comparison of metabolic indices in 12 months of follow-up between early versus 601 late transplantation of MSCs 
602 Table S7. Comparison of immunologic indices in 12 months of follow-up for the early (Early

603 Tx) and late (Late Tx) transplantation groups

604 Table S8. List of follow up events 


\section{References}

606 1. American Diabetes A. Diagnosis and classification of diabetes mellitus. Diabetes care. 2005;28 $607 \quad$ Suppl 1:S37-42.

608 609

610

2. Cho J, D'Antuono M, Glicksman M, Wang J, Jonklaas J. A review of clinical trials: mesenchymal stem cell transplant therapy in type 1 and type 2 diabetes mellitus. American journal of stem cells. 2018;7(4):82-93.

3. Zhang Y, Shen W, Hua J, Lei A, Lv C, Wang H, et al. Pancreatic islet-like clusters from bone marrow mesenchymal stem cells of human first-trimester abortus can cure streptozocin-induced mouse diabetes. Rejuvenation research. 2010;13(6):695-706.

4. Dang Loan PN, Truong Kiet,. Mesenchymal stem cells for diabetes mellitus treatment: new advances. Biomedical Research and Therapy. 2017;4(1):20.

5. Chiang JL, Maahs DM, Garvey KC, Hood KK, Laffel LM, Weinzimer SA, et al. Type 1 Diabetes in Children and Adolescents: A Position Statement by the American Diabetes Association. Diabetes care. 2018;41(9):2026-44.

\section{Organization WH. Global report on diabetes: World Health Organization}

2016 [Available from: https://www.who.int/publications/i/item/9789241565257.

7. Roglic G. WHO Global report on diabetes: A summary. International Journal of Noncommunicable Diseases. 2016;1(1):3-8.

8. International Diabetes Federation. IDF Diabetes Atlas, 9th ed. Brussels, Belgium: 2019. Available at: https://www.diabetesatlas.org [

9. Xu G, Liu B, Sun Y, Du Y, Snetselaar LG, Hu FB, et al. Prevalence of diagnosed type 1 and type 2 diabetes among US adults in 2016 and 2017: population based study. BMJ (Clinical research ed). 2018;362:k1497.

10. Centers for Disease Control and Prevention. National Diabetes Statistics Report, 2020. Atlanta, GA: Centers for Disease Control and Prevention, U.S. Dept of Health and Human Services; 2020.

11. Hu J, Yu X, Wang Z, Wang F, Wang L, Gao H, et al. Long term effects of the implantation of Wharton's jelly-derived mesenchymal stem cells from the umbilical cord for newly-onset type 1 diabetes mellitus. Endocrine journal. 2013;60(3):347-57. 
12. Willcox A, Richardson SJ, Bone AJ, Foulis AK, Morgan NG. Analysis of islet inflammation in human type 1 diabetes. Clinical and experimental immunology. 2009;155(2):173-81.

13. Ezquer M. Mesenchymal Stem Cell Therapy in Type 1 Diabetes Mellitus and Its Main Complications: From Experimental Findings to Clinical Practice. Journal of Stem Cell Research \& Therapy. 2014;04(08).

14. Eizirik DL, Mandrup-Poulsen T. A choice of death--the signal-transduction of immune-mediated beta-cell apoptosis. Diabetologia. 2001;44(12):2115-33.

15. Calafiore R, Montanucci P, Basta G. Stem cells for pancreatic beta-cell replacement in diabetes mellitus: actual perspectives. Current opinion in organ transplantation. 2014;19(2):162-8.

16. Sugianto AI. A Comparison Between Islet And Stem Cell Transplantation For Treatment Of Type 1 Diabetes Mellitus: A Systematic Review. International Journal of Diabetes \& Metabolic Disorders. 2016;1(2):1-14.

17. Dang LT-T, Phan NK, Truong KD. Mesenchymal stem cells for diabetes mellitus treatment: new advances. Biomedical Research and Therapy. 2017;4(1).

18. Liu X, Li X, Zhang N, Wen X. Engineering beta-cell islets or islet-like structures for type 1 diabetes treatment. Medical hypotheses. 2015;85(1):82-4.

19. Wu H, Mahato RI. Mesenchymal stem cell-based therapy for type 1 diabetes. Discov Med. 2014;17(93):139-43.

20. Bluestone JA, Herold K, Eisenbarth G. Genetics, pathogenesis and clinical interventions in type 1 diabetes. Nature. 2010;464(7293):1293-300.

21. Corcione A, Benvenuto F, Ferretti E, Giunti D, Cappiello V, Cazzanti F, et al. Human mesenchymal stem cells modulate B-cell functions. Blood. 2006;107(1):367-72.

22. Li M, Ikehara S. Stem cell treatment for type 1 diabetes. Front Cell Dev Biol. 2014;2:9.

23. Berglund AK, Fortier LA, Antczak DF, Schnabel LV. Immunoprivileged no more: measuring the immunogenicity of allogeneic adult mesenchymal stem cells. Stem Cell Res Ther. 2017;8(1):288.

24. Benthuysen JR, Carrano AC, Sander M. Advances in beta cell replacement and regeneration strategies for treating diabetes. J Clin Invest. 2016;126(10):3651-60. 
25. Shapiro AM, Lakey JR, Ryan EA, Korbutt GS, Toth E, Warnock GL, et al. Islet transplantation in seven patients with type 1 diabetes mellitus using a glucocorticoid-free immunosuppressive regimen. N Engl J Med. 2000;343(4):230-8.

26. An D, Chiu A, Flanders JA, Song W, Shou D, Lu YC, et al. Designing a retrievable and scalable cell encapsulation device for potential treatment of type 1 diabetes. Proc Natl Acad Sci U S A. 2018;115(2):E263-E72.

27. Boettler T, Schneider D, Cheng Y, Kadoya K, Brandon EP, Martinson L, et al. Pancreatic Tissue Transplanted in TheraCyte Encapsulation Devices Is Protected and Prevents Hyperglycemia in a Mouse Model of Immune-Mediated Diabetes. Cell Transplant. 2016;25(3):609-14.

28. Gerace D, Martiniello-Wilks R, Nassif NT, Lal S, Steptoe R, Simpson AM. CRISPR-targeted genome editing of mesenchymal stem cell-derived therapies for type 1 diabetes: a path to clinical success? Stem Cell Res Ther. 2017;8(1):62.

29. Bluestone JA, Buckner JH, Fitch M, Gitelman SE, Gupta S, Hellerstein MK, et al. Type 1 diabetes immunotherapy using polyclonal regulatory T cells. Sci Transl Med. 2015;7(315):315ra189.

30. Moreira A, Kahlenberg S, Hornsby P. Therapeutic potential of mesenchymal stem cells for diabetes. J Mol Endocrinol. 2017;59(3):R109-R20.

31. Lee RH, Pulin AA, Seo MJ, Kota DJ, Ylostalo J, Larson BL, et al. Intravenous hMSCs improve myocardial infarction in mice because cells embolized in lung are activated to secrete the antiinflammatory protein TSG-6. Cell Stem Cell. 2009;5(1):54-63.

32. Dominici M, Le Blanc K, Mueller I, Slaper-Cortenbach I, Marini F, Krause D, et al. Minimal criteria for defining multipotent mesenchymal stromal cells. The International Society for Cellular Therapy position statement. Cytotherapy. 2006;8(4):315-7.

33. Sharpe PT. Dental mesenchymal stem cells. Development (Cambridge, England). 2016;143(13):2273-80.

34. Huang GT, Gronthos S, Shi S. Mesenchymal stem cells derived from dental tissues vs. those from other sources: their biology and role in regenerative medicine. Journal of dental research. 2009;88(9):792-806.

35. Brown C, McKee C, Bakshi S, Walker K, Hakman E, Halassy S, et al. Mesenchymal stem cells: Cell therapy and regeneration potential. Journal of tissue engineering and regenerative medicine. 2019;13(9):1738-55. 
36. Mabed M, Shahin M. Mesenchymal stem cell-based therapy for the treatment of type 1 diabetes mellitus. Current stem cell research \& therapy. 2012;7(3):179-90.

37. Ra JC, Shin IS, Kim SH, Kang SK, Kang BC, Lee HY, et al. Safety of intravenous infusion of human adipose tissue-derived mesenchymal stem cells in animals and humans. Stem cells and development. 2011;20(8):1297-308.

38. Lee RH, Seo MJ, Reger RL, Spees JL, Pulin AA, Olson SD, et al. Multipotent stromal cells from human marrow home to and promote repair of pancreatic islets and renal glomeruli in diabetic NOD/scid mice. Proc Natl Acad Sci U S A. 2006;103(46):17438-43.

39. Fiorina P, Jurewicz M, Augello A, Vergani A, Dada S, La Rosa S, et al. Immunomodulatory function of bone marrow-derived mesenchymal stem cells in experimental autoimmune type 1 diabetes. J Immunol. 2009;183(2):993-1004.

40. Jurewicz M, Yang S, Augello A, Godwin JG, Moore RF, Azzi J, et al. Congenic mesenchymal stem cell therapy reverses hyperglycemia in experimental type 1 diabetes. Diabetes. 2010;59(12):313947.

41. Ezquer F, Ezquer M, Contador D, Ricca M, Simon V, Conget P. The antidiabetic effect of mesenchymal stem cells is unrelated to their transdifferentiation potential but to their capability to restore Th1/Th2 balance and to modify the pancreatic microenvironment. Stem Cells. 2012;30(8):1664-74.

42. Abdi R, Fiorina P, Adra CN, Atkinson M, Sayegh MH. Immunomodulation by mesenchymal stem cells: a potential therapeutic strategy for type 1 diabetes. Diabetes. 2008;57(7):1759-67.

43. Sordi V, Malosio ML, Marchesi F, Mercalli A, Melzi R, Giordano T, et al. Bone marrow mesenchymal stem cells express a restricted set of functionally active chemokine receptors capable of promoting migration to pancreatic islets. Blood. 2005;106(2):419-27.

44. Sohni A, Verfaillie CM. Mesenchymal stem cells migration homing and tracking. Stem Cells Int. 2013;2013:130763.

45. Zhao Q, Ren H, Han Z. Mesenchymal stem cells: Immunomodulatory capability and clinical potential in immune diseases. Journal of Cellular Immunotherapy. 2016;2(1):3-20.

46. Emadedin M, Ghorbani Liastani M, Fazeli R, Mohseni F, Moghadasali R, Mardpour S, et al. LongTerm Follow-up of Intra-articular Injection of Autologous Mesenchymal Stem Cells in Patients with Knee, Ankle, or Hip Osteoarthritis. Archives of Iranian medicine. 2015;18(6):336-44. 
47. Navabi R, Negahdari B, Hajizadeh-Saffar E, Hajinasrollah M, Jenab Y, Rabbani S, et al. Combined therapy of mesenchymal stem cells with a GLP-1 receptor agonist, liraglutide, on an inflammatorymediated diabetic non-human primate model. Life Sci. 2021;276:119374.

48. De Miguel MP, Fuentes-Julian S, Blazquez-Martinez A, Pascual CY, Aller MA, Arias J, et al. Immunosuppressive properties of mesenchymal stem cells: advances and applications. Current molecular medicine. 2012;12(5):574-91.

726

727

728

729

730

49. Wood J, Peters A. The type 1 diabetes self-care manual : a complete guide to type 1 diabetes across the lifespan for people with diabetes, parents, and caregivers: American Diabetes Association; 2018.

50. Le Blanc K, Rasmusson I, Sundberg B, Gotherstrom C, Hassan M, Uzunel M, et al. Treatment of severe acute graft-versus-host disease with third party haploidentical mesenchymal stem cells. Lancet. 2004;363(9419):1439-41.

51. Le Blanc K, Frassoni F, Ball L, Locatelli F, Roelofs H, Lewis I, et al. Mesenchymal stem cells for treatment of steroid-resistant, severe, acute graft-versus-host disease: a phase II study. Lancet. 2008;371(9624):1579-86.

52. von Bahr L, Sundberg B, Lonnies L, Sander B, Karbach H, Hagglund H, et al. Long-term complications, immunologic effects, and role of passage for outcome in mesenchymal stromal cell therapy. Biol Blood Marrow Transplant. 2012;18(4):557-64.

53. von Bahr L, Batsis I, Moll G, Hagg M, Szakos A, Sundberg B, et al. Analysis of tissues following mesenchymal stromal cell therapy in humans indicates limited long-term engraftment and no ectopic tissue formation. Stem Cells. 2012;30(7):1575-8.

54. Carlsson PO, Schwarcz E, Korsgren O, Le Blanc K. Preserved beta-cell function in type 1 diabetes by mesenchymal stromal cells. Diabetes. 2015;64(2):587-92.

55. Karussis D, Karageorgiou C, Vaknin-Dembinsky A, Gowda-Kurkalli B, Gomori JM, Kassis I, et al. Safety and immunological effects of mesenchymal stem cell transplantation in patients with multiple sclerosis and amyotrophic lateral sclerosis. Arch Neurol. 2010;67(10):1187-94.

56. He X, Wang Q, Zhao Y, Zhang H, Wang B, Pan J, et al. Effect of Intramyocardial Grafting Collagen Scaffold With Mesenchymal Stromal Cells in Patients With Chronic Ischemic Heart Disease: A Randomized Clinical Trial. JAMA Network Open. 2020;3(9):e2016236-e. 
57. Wang L, Huang S, Li S, Li M, Shi J, Bai W, et al. Efficacy and Safety of Umbilical Cord Mesenchymal Stem Cell Therapy for Rheumatoid Arthritis Patients: A Prospective Phase I/II Study. Drug design, development and therapy. 2019;13:4331-40.

58. Kabat M, Bobkov I, Kumar S, Grumet M. Trends in mesenchymal stem cell clinical trials 20042018: Is efficacy optimal in a narrow dose range? Stem cells translational medicine. 2020;9(1):1727.

59. Lalu MM, McIntyre L, Pugliese C, Fergusson D, Winston BW, Marshall JC, et al. Safety of cell therapy with mesenchymal stromal cells (SafeCell): a systematic review and meta-analysis of clinical trials. PLoS One. 2012;7(10):e47559.

60. Rogers CJ, Harman RJ, Bunnell BA, Schreiber MA, Xiang C, Wang FS, et al. Rationale for the clinical use of adipose-derived mesenchymal stem cells for COVID-19 patients. Journal of translational medicine. 2020;18(1):203.

61. Ding HR, Wang JL, Tang ZT, Wang Y, Zhou G, Liu Y, et al. Mesenchymal Stem Cells Improve Glycometabolism and Liver Regeneration in the Treatment of Post-hepatectomy Liver Failure. Front Physiol. 2019;10:412.

62. Kukreja A, Cost G, Marker J, Zhang C, Sun Z, Lin-Su K, et al. Multiple immuno-regulatory defects in type-1 diabetes. J Clin Invest. 2002;109(1):131-40.

63. Lu J, Liu J, Li L, Lan Y, Liang Y. Cytokines in type 1 diabetes: mechanisms of action and immunotherapeutic targets. Clin Transl Immunology. 2020;9(3):e1122.

64. Rapoport MJ, Mor A, Vardi P, Ramot Y, Winker R, Hindi A, et al. Decreased secretion of Th2 cytokines precedes Up-regulated and delayed secretion of Th1 cytokines in activated peripheral blood mononuclear cells from patients with insulin-dependent diabetes mellitus. J Autoimmun. 1998;11(6):635-42.

65. Kleffel S, Vergani A, Tezza S, Ben Nasr M, Niewczas MA, Wong S, et al. Interleukin-10+ regulatory B cells arise within antigen-experienced CD40+ B cells to maintain tolerance to islet autoantigens. Diabetes. 2015;64(1):158-71.

66. Robert S, Gysemans C, Takiishi T, Korf H, Spagnuolo I, Sebastiani G, et al. Oral delivery of glutamic acid decarboxylase (GAD)-65 and IL10 by Lactococcus lactis reverses diabetes in recentonset NOD mice. Diabetes. 2014;63(8):2876-87. 
67. Zheng XX, Steele AW, Hancock WW, Stevens AC, Nickerson PW, Roy-Chaudhury P, et al. A noncytolytic IL-10/Fc fusion protein prevents diabetes, blocks autoimmunity, and promotes suppressor phenomena in NOD mice. J Immunol. 1997;158(9):4507-13.

68. Ishigame H, Zenewicz LA, Sanjabi S, Licona-Limon P, Nakayama M, Leonard WJ, et al. Excessive Th1 responses due to the absence of TGF-beta signaling cause autoimmune diabetes and dysregulated Treg cell homeostasis. Proc Natl Acad Sci U S A. 2013;110(17):6961-6.

69. Teros T, Hakala R, Ylinen L, Liukas A, Arvilommi P, Sainio-Pollanen S, et al. Cytokine balance and lipid antigen presentation in the NOD mouse pancreas during development of insulitis. Pancreas. 2000;20(2):191-6.

70. Campbell IL, Hobbs MV, Dockter J, Oldstone MB, Allison J. Islet inflammation and hyperplasia induced by the pancreatic islet-specific overexpression of interleukin-6 in transgenic mice. Am $\mathbf{J}$ Pathol. 1994;145(1):157-66.

71. Chen YL, Qiao YC, Pan YH, Xu Y, Huang YC, Wang YH, et al. Correlation between serum interleukin-6 level and type 1 diabetes mellitus: A systematic review and meta-analysis. Cytokine. 2017;94:14-20.

72. Dahlen E, Dawe K, Ohlsson L, Hedlund G. Dendritic cells and macrophages are the first and major producers of TNF-alpha in pancreatic islets in the nonobese diabetic mouse. J Immunol. 1998;160(7):3585-93.

73. Green EA, Eynon EE, Flavell RA. Local expression of TNFalpha in neonatal NOD mice promotes diabetes by enhancing presentation of islet antigens. Immunity. 1998;9(5):733-43.

74. Mastrandrea L, Yu J, Behrens T, Buchlis J, Albini C, Fourtner S, et al. Etanercept treatment in children with new-onset type 1 diabetes: pilot randomized, placebo-controlled, double-blind study. Diabetes care. 2009;32(7):1244-9.

75. Maccario R, Podesta M, Moretta A, Cometa A, Comoli P, Montagna D, et al. Interaction of human mesenchymal stem cells with cells involved in alloantigen-specific immune response favors the differentiation of $\mathrm{CD} 4+\mathrm{T}$-cell subsets expressing a regulatory/suppressive phenotype. Haematologica. 2005;90(4):516-25.

76. Boumaza I, Srinivasan S, Witt WT, Feghali-Bostwick C, Dai Y, Garcia-Ocana A, et al. Autologous bone marrow-derived rat mesenchymal stem cells promote PDX-1 and insulin expression in the islets, alter $\mathrm{T}$ cell cytokine pattern and preserve regulatory $\mathrm{T}$ cells in the periphery and induce sustained normoglycemia. J Autoimmun. 2009;32(1):33-42. 
77. Zhang R, Liu Y, Yan K, Chen L, Chen XR, Li P, et al. Anti-inflammatory and immunomodulatory mechanisms of mesenchymal stem cell transplantation in experimental traumatic brain injury. $\mathbf{J}$ Neuroinflammation. 2013;10(1):106.

78. Chen C, Cohrs CM, Stertmann J, Bozsak R, Speier S. Human beta cell mass and function in diabetes: Recent advances in knowledge and technologies to understand disease pathogenesis. Molecular metabolism. 2017;6(9):943-57.

79. Sherry NA, Tsai EB, Herold KC. Natural history of beta-cell function in type 1 diabetes. Diabetes. 2005;54 Suppl 2:S32-9.

80. Wasserman DH, Zinman B. Exercise in Individuals With IDDM. Diabetes care. 1994;17(8):924.

81. Sato Y, Nagasaki M, Nakai N, Fushimi T. Physical Exercise Improves Glucose Metabolism in Lifestyle-Related Diseases. Experimental Biology and Medicine. 2003;228(10):1208-12.

82. Couper JJ, Haller MJ, Ziegler AG, Knip M, Ludvigsson J, Craig ME, et al. ISPAD Clinical Practice Consensus Guidelines 2014. Phases of type 1 diabetes in children and adolescents. Pediatr Diabetes. 2014;15 Suppl 20:18-25.

83. Fonolleda M, Murillo M, Vazquez F, Bel J, Vives-Pi M. Remission Phase in Paediatric Type 1 Diabetes: New Understanding and Emerging Biomarkers. Horm Res Paediatr. 2017;88(5):307-15.

84. Institute R. Phase I Clinical Trial to Examine the Safety of Transplantation of Mesenchymal Stem Cells in New-onset Type 1 Diabetes Patients. 2015-2020, Identifier IRCT2016070428786N1 (Available from: https://en.irct.ir/trial/23256) [

85. Institute R. Mesenchymal Stem Cells Transplantation in Newly Diagnosed Type-1 Diabetes Patients. 2015-2020, Identifier NCT04078308 (Available from: https://ClinicalTrials.gov/show/NCT04078308) [updated July 6. 


\section{Supplementary Files}

This is a list of supplementary files associated with this preprint. Click to download.

- MSCArticleSupplementaryMaterial.pdf 